\title{
Mechanisms of smart waterflooding in carbonate oil reservoirs - A review
}

Hao, Jiasheng; Mohammadkhani, Samira; Shahverdi, Hamidreza; Esfahany, Mohsen Nasr; Shapiro, Alexander

Published in:

Journal of Petroleum Science and Engineering

Link to article, DOI:

10.1016/j.petrol.2019.04.049

Publication date:

2019

Document Version

Peer reviewed version

Link back to DTU Orbit

Citation (APA):

Hao, J., Mohammadkhani, S., Shahverdi, H., Esfahany, M. N., \& Shapiro, A. (2019). Mechanisms of smart waterflooding in carbonate oil reservoirs - A review. Journal of Petroleum Science and Engineering, 179, 276291. https://doi.org/10.1016/j.petrol.2019.04.049

\section{General rights}

Copyright and moral rights for the publications made accessible in the public portal are retained by the authors and/or other copyright owners and it is a condition of accessing publications that users recognise and abide by the legal requirements associated with these rights.

- Users may download and print one copy of any publication from the public portal for the purpose of private study or research.

- You may not further distribute the material or use it for any profit-making activity or commercial gain

- You may freely distribute the URL identifying the publication in the public portal

If you believe that this document breaches copyright please contact us providing details, and we will remove access to the work immediately and investigate your claim. 


\section{Accepted Manuscript}

Mechanisms of smart waterflooding in carbonate oil reservoirs - A review

Jiasheng Hao, Samira Mohammadkhani, Hamidreza Shahverdi, Mohsen Nasr

Esfahany, Alexander Shapiro

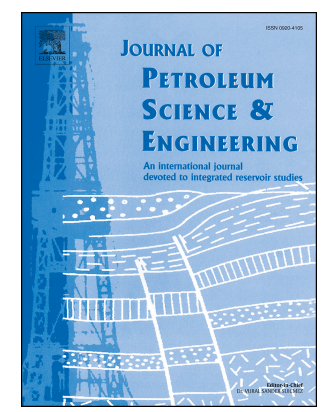

PII:

S0920-4105(19)30386-9

DOI:

https://doi.org/10.1016/j.petrol.2019.04.049

Reference: PETROL 5988

To appear in: Journal of Petroleum Science and Engineering

Received Date: 9 January 2019

Revised Date: 12 April 2019

Accepted Date: 14 April 2019

Please cite this article as: Hao, J., Mohammadkhani, S., Shahverdi, H., Esfahany, M.N., Shapiro, A., Mechanisms of smart waterflooding in carbonate oil reservoirs - A review, Journal of Petroleum Science and Engineering (2019), doi: https://doi.org/10.1016/j.petrol.2019.04.049.

This is a PDF file of an unedited manuscript that has been accepted for publication. As a service to our customers we are providing this early version of the manuscript. The manuscript will undergo copyediting, typesetting, and review of the resulting proof before it is published in its final form. Please note that during the production process errors may be discovered which could affect the content, and all legal disclaimers that apply to the journal pertain. 


\title{
Mechanisms of smart waterflooding in carbonate oil reservoirs - a review
}

Jiasheng Hao ${ }^{\mathrm{b}, \mathrm{c}}$, Samira Mohammadkhani ${ }^{\mathrm{a}, \mathrm{b}, \mathrm{c}}$, Hamidreza Shahverdi ${ }^{\mathrm{a}}$, Mohsen Nasr Esfahany ${ }^{\mathrm{a}}$, Alexander Shapiro $^{\mathrm{c}^{*}}$

${ }^{a}$ Department of Chemical Engineering, Isfahan University of Technology, Isfahan 84156-83111, Iran.

${ }^{\mathrm{b}}$ Danish Hydrocarbon Research and Technology Centre (Centre for Oil and Gas - DTU), Elektrovej 375, DK-2800, Lyngby, Denmark.

${ }^{c}$ Center for Energy Resources Engineering (CERE), Department of Chemical and Biochemical Engineering, Technical University of Denmark, Denmark.

*Corresponding authors: Alexander Shapiro ash@kt.dtu.dk; Hamidreza Shahverdi hr_shahverdi@cc.iut.ac.ir

Jiasheng Hao and Samira Mohammadkhani have equal responsibility for the paper as its main authors.

\begin{abstract}
The goal of the present paper is to provide a comprehensive review of the literature describing the physical and chemical mechanisms for enhanced oil recovery under smart waterflooding in carbonate reservoirs. Advanced, or smart waterflooding is a term denoting directed alteration of the ionic composition of the injected brine in order to achieve a better oil recovery, in particular, the low salinity flooding. While injection of a low salinity brine in sandstones is well described, the acting mechanisms of advanced waterflooding are not fully clarified, and only few reservoir-scale tests have been carried out. Demonstration and comparison of the different phenomena explaining the effect of smart waterflooding are the goals of the present review. Unlike the previous such reviews, we do not only concentrate on the phenomena occurring on the rock-brine-oil interfaces, but also address dynamic phenomena caused by flow, like fluid diversion and emulsification. The paper comprises an up-to-date information, classification and guidance and, consequently, is intended to serve advancing the research in the area of smart waterflooding in carbonates.
\end{abstract}

Keywords: Engineered water injection; smart waterflooding; low salinity; carbonates; physical and chemical mechanisms of recovery; improved oil recovery 


\section{Introduction}

Smart waterflooding in carbonate rocks has recently drawn an increasing attention. For sandstone rocks smart water flooding is often identified with the low salinity flooding (Bartels et al., 2019; Afekare and Radonjic, 2017; Sohal et al., 2016). However, in carbonates the approaches to smart waterflooding may be more diverse. In this work, the term 'smart waterflooding' is used to denote production of additional oil by injection of a specially prepared brine, which has a different ionic composition from the formation water or previously injected brine. Although injection of low salinity water is applicable also in carbonates (Derkani et al., 2018), addition or removal of particular salts containing calcium, magnesium, sulfate and other ions may also be an option.

Compared to other methods applicable to enhancement in oil recovery from carbonates, water is easy to inject and is usually relatively inexpensive, although desalination and getting fresh water may be a challenge in some places (Yousef et al., 2011). Injection of low salinity brine for oil recovery was applied long ago (Goolsby and Anderson, 1964; Hallenbeck et al., 1991) and was recognized as a method for enhanced oil recovery for at least fifty years (Bernard G.G., 1967). Active development of this recovery method started by revealing the acting mechanism of low salinity waterflooding in sandstones (Tang and Morrow, 1999). This form of smart waterflooding has been successfully applied in sandstone reservoirs (Aghaeifar et al., 2015; Alvarado et al., 2014; Austad et al., 2010; Jackson et al., 2016; Kuznetsov et al., 2015; Mahani et al., 2015; Morrow and Buckley, 2011; RezaeiDoust et al., 2011; Rotondi et al., 2014; Shehata and Nasr ElDin, 2015; Suman et al., 2014; Zeinijahromi et al., 2015), followed by development of desalination technologies (Ayirala and Yousef, 2016). However, application of smart waterflooding for development of carbonate reservoirs has so far been limited to separate pilot tests (Rassenfoss, 2016; Yousef et al., 2012a).

A possible reason for limited application of smart waterflooding in carbonates is thatthe involved physico-chemical mechanisms are not fully clarified yet. The literature suggests different recovery mechanisms, and the experimental data look sometimes controversial. Absence of clarity about the working mechanisms results in impossibility of formulating the operating conditions for successful application of smart waterflooding in carbonates, contrary to sandstones, where the LoSal ${ }^{\mathrm{TM}}$ technology was successfully implemented by BP (Lager et al., 2008b).

Recently, several review papers have discussed smart waterflooding from different angles (Jackson et al., 2016; Afekare and Radonjic, 2017; Ayirala and Yousef, 2016; Bartels et al., 2019; Derkani et al., 2018; Sheng, 2014; Sohal et al., 2016). They have put a great effort on explaining the chemical and physical processes, laboratory and field tests, as well as required working conditions for low salinity flooding. Extensive work has been put on comparing and grouping the reported experimental observations and finding the links and inconsistencies between similar studies. Analysis of the working mechanisms for low salinity flooding has also been carried out, especially, regarding solid-liquid and liquid-liquid interface interactions (Derkani et al., 2018). The disucssion has also been extended to a more fundamental level, of the interaction between the different length and time scales under low salinity flooding (Bartels et 
al., 2019). Still, some mechanisms have remained uncovered by the current reviews, or described only with regard to low salinity flooding. Some researchers applied surfactants and polymers assisted smart water and low salinity brines to improve oil recovery (Alagic et al., 2011; Gupta et al., 2011; Karimi et al., 2016; Shaddel and Tabatabae-Nejad, 2015; Shaker Shiran and Skauge, 2013; Standnes and Austad, 2000a, 2000b; Sun et al., 2014). This is outside the scope of the present review.

The present review paper aims at providing a complete overview over the oil recovery mechanisms under smart waterflooding in carbonate rocks, and experimental evidence supporting or contradicting these mechanisms. We have tried to classify the chemical and physical phenomena explaining positive effects of smart waterflooding. Such classification may only be approximate and relative, since (as realized by many authors) experimental behavior of the rock-fluid system and additional oil production are the results of multiple mechanisms acting simultaneously. We have approximately divided the phenomena observed in a oil-brine-rock system into static and dynamic phenomena.

The static phenomena may in principle be observed and studied in the experiments where no flow is required. Such phenomena like wettability alteration or compaction are static. It may happen, however, that the static mechanisms manifest itself differently in the flow-through experiments (like selective compaction may result in flow diversion).

On the contrary, dynamic phenomena require appearance of the flow. A characteristic example is flow diversion due to plugging of high-permeable areas. There are many phenomena that are on the border between static and dynamic, like formation of emulsions. We have included them into the dynamic phenomena, since in most cases they require liquid movement (snap-off, vibrations) in order to develop to a significant extent.

Most of the literature is related to the static mechanisms, investigating chemical and physicochemical transformations occurring on the oil-rock, water-rock or water-oil interfaces, as reflected in the previous reviews (Mahani et al., 2015; Sohal et al., 2016; Derkani et al., 2018). We have tried, on the other hand, to keep the discussion more balanced, overviewing also mechanisms that have not been addressed as extensively. In sandstones, it is a combination of the static and dynamic mechanisms (surface chemistry and release of fines) that has resulted in successful application of the low salinity flooding. A similar combination is probably required to successfully apply waterflooding in carbonate rocks.

The paper is organized as follows. Section 2 discusses the static mechanisms relevant to smart waterflooding. Section 2.1 covers phenomena related to wettability alteration, like surface ion exchange, surface charge alteration, mineral dissolution or precipitation. Other static mechanisms, like modification of the oil-brine interface, viscosity reduction and rock compaction, are reviewed in section 2.2. Section 3 discusses dynamic mechanisms, like those related to general flow dynamics, heterogeneity, production of fines and emulsions. The paper ends with the general discussion. 


\section{Static mechanisms}

In this section, the static phenomena that can appear without any flow through porous media are presented. Wettability alteration, surface ion exchange, change of the surface charge, rock dissolution, interfacial tension and oil viscosity reduction, as well as rock compaction, fall into this category.

\subsection{Wettability related mechanisms}

\subsubsection{Wettability alteration}

Wettability alteration is usually not a separate mechanism, but an effect produced by other microscale mechanisms, such as surface ion exchange, surface charge change, double layer expansion, mineral dissolution. However, some authors refer to wettability alteration without explaining, or giving multiple explanations of, how it appears. In order to cover such cases, we present a review accounting wettability alteration as a separate phenomenon. Particular microscale mechanisms that may lead to wettability alteration are considered further in the review.

\section{Measurement of wettability}

In petroleum applications, there are several non-equivalent ways to quantify wettability. The wettability of a solid surface can be specified by measuring the contact angle of an oil drop on the surface (Dandekar, 2013). On the other hand, wettability of a porous medium, namely the rock, can be described by Amott-Harvey, USBM, or similar indices. Another method, based on the difference of sulfate and thiocyanate adsorption, was introduced lately to measure the wettability of chalk (Strand et al., 2006). The authors claim that it is faster than the AmottHarvey method and provides similar results for chalk. The methods based on the electrical resistivity and NMR spectroscopy have also been applied (Katika et al., 2018).

\section{Effect of oil composition}

The acid and base number of oil may have an impact on the initial chalk wettability, which dictates the effectiveness of wettability alteration by smart water flooding. It was pointed out that oil wet surfaces are not preferable for wettability alteration if an oil does not contain substantial amount of acidic components (Austad and Standnes, 2003).

The acid number (AN) is the major parameter that determines rock wettability (Zhang and Austad, 2005). Usually, the carbonate rock surface is positively charged. This facilitates adsorption of the negatively charged carboxylic groups, whose amount is indicated by the AN. Therefore, the higher the AN, the more oil-wet the rock can be (Standnes and Austad 2000). Austad and Standnes (2003) studied the impact of AN on wettability of Stevns Klint chalk by imbibition experiments. It was shown that oil recovery substantially decreased with increased AN. The difference in recovery was as large as $30 \%$ for the AN varying from 0.08 to 0.70 .

On the other hand, the base number $(\mathrm{BN})$ plays a minor role on rock wettability. Puntervold $e t$ al. (2007) performed a series of imbibition experiments with the oils having a constant AN (0.5 $\mathrm{mg} \mathrm{KOH} / \mathrm{g})$, but a wide range of $\mathrm{BN}(0.178-2.08 \mathrm{mg} \mathrm{KOH} / \mathrm{g})$. The final recovery varied within only $10 \%$, which is much less significant than the variation obtained by changing the AN. 
Beside AN/BN, other details of the oil composition, such as fraction of heavy components (resins, asphaltenes) and viscosity also have impact on smart water flooding. Zahid et al. (2010) carried out core flooding experiments with crude oils from Latin America, North Sea and Middle East, which have a wide range of asphaltene content. The additional recovery by injecting modified seawater varied between $1.2 \%$ to $4.5 \%$ for different oils.

\section{Effect of potential determining ions}

It has been reported by many researchers that certain ions in a brine may promote wettability alteration of the rock surface. Rezaei Gomari and Hamouda (2006) performed contact angle measurements to investigate the effect of $\mathrm{NaCl}, \mathrm{MgCl}_{2}$ and $\mathrm{Na}_{2} \mathrm{SO}_{4}$ on wettability alteration. Contact angles of fatty acid drops on calcite surface were measured in different brine environments. It was observed that the $\mathrm{MgCl}_{2}$ and $\mathrm{Na}_{2} \mathrm{SO}_{4}$ solutions changed wettability more effectively than the $\mathrm{NaCl}$ solution. Alshakhs and Kovscek, 2016, also studied the impact of $\mathrm{Mg}^{2+}$ and $\mathrm{SO}_{4}{ }^{2-}$ ions on the contact angle. The measurements were performed on an Iceland spar crystal chip at ambient conditions. It was observed that the contact angle was reduced from 95.7 to 55.4 degrees when the aqueous phase varied from seawater to a $\mathrm{MgSO}_{4}$ rich brine.

In agreement with the above observations, (Rashid et al., 2015) found that $\mathrm{Mg}^{2+}$ alone could change wettability of the rock surface, and presence of $\mathrm{SO}_{4}{ }^{2-}$ could enhance wettability alteration. Karimi et al.(2016) observed also that wettability alteration is more pronounced when both $\mathrm{Mg}^{2+}$ and $\mathrm{SO}_{4}{ }^{2-}$ are present. Similar observations regarding the effect of $\mathrm{Mg}^{2+}$ and $\mathrm{SO}_{4}{ }^{2-}$ on the contact angle were reported by Karoussi and Hamouda, (2007). However, in contradiction with these observations, Gupta et al. (2011) found that $\mathrm{SO}_{4}{ }^{2-}$ and $\mathrm{Ca}^{2+}$ ions play a more important role than $\mathrm{Mg}^{2+}$ ions. This was established by the contact angle measurements at $90{ }^{\circ} \mathrm{C}$ with a model oil consisting of n-decane with $0.15 \%$ wt cyclohexanepentaonic acid.

In surprising contradiction with the above results, Lashkarbolooki et al. (2017) reported that distilled water altered the wettability of a carbonate reservoir rock from strongly oil-wet to strongly water-wet, while high concentrations of $\mathrm{NaCl}, \mathrm{CaCl}_{2}, \mathrm{MgCl}_{2}$ solutions did not significantly change the contact angle. Meanwhile, $\mathrm{KCl}$ was found to be able to alter the wettability to strongly water-wet. A capability of the different salts to alter wettability was reported to be: $\mathrm{KCl}>\mathrm{DIW}>\mathrm{NaCl}>\mathrm{MgCl}_{2}>\mathrm{CaCl}_{2}$.

\section{Effect of low salinity brine}

Injection of low salinity brine may also make the chalk more water-wet. However, the reported results of contact angle measurements with low salinity brines are rather controversial. Yousef $e t$ al. (2012) performed such measurements under reservoir conditions and pointed out that diluted seawater makes the reservoir rock more water-wet. Mahani et al. (2015) also observed lower contact angles for seawater and diluted seawater than for the formation water. However, Mohsenzadeh et al. (2016) did not observe a significant change in contact angles by low salinity brines. 
Patil et al. (2008) measured the Amott-Harvey indices of the cores flooded by a low salinity brine. The cores became more water-wet after flooding. It was concluded that mechanisms involved in low salinity water injection (LSWI) resemble those engaged in alkaline flooding.

Al-Shalabi et al. (2014) investigated the main mechanisms behind LSWI on oil recovery from carbonates through history matching of the results of the core flooding experiments. The experimental data used in this study were reported by Mohanty and Chandrasekhar, (2013). Wettability alteration was shown to be the main mechanism of the LSWI. Incremental oil recovery was found to be mainly controlled by the relative permeability for oil, rather than for water. A difference between the experimental and modeling outputs was attributed to heterogeneity of the core samples.

Sheng et al. (2010) compared the effect of wettability alteration under different oil-water interfacial tensions, in both fractured and non-fractured dolomite reservoir cores. Input data were obtained from the experiments of Hirasaki and Zhang (2004). It was concluded from the simulation that wettability alteration played an effective role only when IFT was high, which was more important at the early stages of the experiments.

Zaeri et al. (2018a, 2018b) carried out Amott (imbibition) tests with the reservoir oils and the carbonate rock materials from Iranian petroleum reservoirs. It was showed that there is an optimum degree of dilution corresponding to a maximum recovery. The recovery under imbibition of the 20 times diluted brine was found to be higher than under imbibition of the distilled water. These results were confirmed by measurements of the contact angles. It was also found that a higher permeability promotes the recovery by the low salinity brine. The authors explained this effect by interplay between viscous and capillary forces.

\section{Salinity gradients}

Shehata et al. (2014) injected brines with different ionic strength into limestone cores at $195^{\circ} \mathrm{F}$. The main conclusion of their work was that a sudden change in salinity is more important than salinity itself. Mobility of the oil drops under varying salinity in the surrounded brine may be caused by the effect called diffusiophoresis (Prieve and Roman, 1987). A double layer around a drop in the surrounding concentration gradient may be non-uniform, which creates a moving force.

Zaeri et al. ( 2018b) showed that recovery by imbibition of the low salinity water increases much if the rock contains initially a certain (but not-so-large) amount of the saline connate water. Increasing the initial water saturation to a certain value improves the oil recovery, but any further increase has a negative impact. As discussed by Zaeri et al. (2018a), existence of initial water saturation may facilitate ion transport between the rock surface and the brine leading to the rock wettability alteration. Another explanation might be, though, that the formed salinity gradients 
cause diffusiophoresis of the oil drops and their joining of the infinite oil cluster. This mechanism needs further study.

\section{Effect of temperature}

It was reported by various researchers that temperature affects wettability alteration. Schembre $e t$ al. (2006) measured the Amott wettability indices for sandstone and carbonate cores. It was shown that increased temperature can change the rock wettability from intermediate and low water-wet to strongly water-wet. Hamouda and Rezaei Gomari (2006) reported also that increased temperature could make calcite surface more water-wet. Contact angle measurements confirmed these observations: contact angle decreased with increased temperature, indicating a more water-wet surface (Karoussi and Hamouda, 2007). A positive effect of high temperature was also reported by Zaeri et al. (2018a, 2018b).

However, there is a different possibility. Anhydrate dissolution by low salinity flooding may supply $\mathrm{Ca}^{2+}$ and $\mathrm{SO}_{4}{ }^{2-}$ to the injection brine in-situ, which are among the key ions to trigger wettability alteration (Austad et al., 2015; Strand et al., 2017). If the solubility of anhydrate in a particular brine decreases with increased temperature, the amount of $\mathrm{Ca}^{2+}$ and $\mathrm{SO}_{4}{ }^{2-}$ supplied by anhydrate dissolution may also decrease. This makes high temperatures unfavorable for wettability alteration.

\section{Discussion}

It can be seen from the above review that the observations of wettability alteration mechanism are not always consistent. Most studies used the contact angle as an indicator of wettability. However, some important information, such as surface roughness of the solid substrate and the time scale of the measurements, was rarely reported. These factors could largely affect the measurements. The contact angle is not only related to the brine composition, but also to the oil composition and rock mineralogy (Buckley et al. 1998). Hence, the results reported by different researchers, who applied different materials in their experiments, may not be directly comparable.

Another factor that is worth discussing is an optimal state of wettability for oil production. While most published results imply that a more water-wet rock is preferred for oil production, Skauge and Ottesen (2002) pointed out that an intermediate-wet state is most efficient. They summarized waterflooding results from 30 fields from the North Sea area and plotted residual oil saturation against Amott-Harvey index. The lowest residual oil saturation was found when the index was around zero (which indicates intermediate-wet rock). A possible explanation is that the magnitude of capillary pressure is minimized at the intermediate-wet state, which helps mobilizing small oil drops in the pore space by flooding (the Jamin effect). Another explanation is that intermediate wettability reduces the snap-off and entrapment of the residual oil. This has been observed in micro-CT experiments and numerical simulations performed on the capillary networks (Høiland et al., 2007). 
Importance of the wettability change has also been questioned. The study of Katika et al. (2018) indicates that enhanced recovery due to wettability change was unlikely in that case since the NMR measurement did not show any wettability alteration under smart water flooding. Other factors, like pore collapse and fines precipitation, might be more important in this case.

Wettability, after all, is a macroscopic property of the two liquids on the solid substrate. The wettability alteration may be caused by the different physical phenomena. It may be that these phenomena, but not wettability itself, that result in better recovery. When studying wettability, one tends to focus on one or two parameters or microscopic mechanisms, often leaving other parameters uncontrolled. This could be a reason why wettability still remains mysterious after so many years of research. In the following sections, we present a number of particular chemical/physical wettability modifying mechanisms that may potentially increase the recovery.

\subsubsection{Surface ion exchange}

Surface ion exchange is often believed to be the main mechanism for improved oil recovery by smart waterflooding. It acts via detachment of polar components of oil from the surface; changing the surface charge; expanding the double layer; and, finally, altering the wettability of the rock surface. In this part, we discuss experimental studies based on this mechanism.

\section{Description and evidence of the mechanism}

The mechanism of multi-ion exchange was first proposed by Zhang et al. (2007) based on a series of imbibition experiments and chromatography wettability tests (Zhang et al., 2006; Zhang and Austad, 2006). It was suggested that adsorption of negatively charged ion $\mathrm{SO}_{4}{ }^{2-}$ onto positively charged chalk surface reduces the total charge of the surface. Then, positively charged $\mathrm{Ca}^{2+}$ and $\mathrm{Mg}^{2+}$ ions could gain access to the surface.

$\mathrm{Ca}^{2+}$ may react with the adsorbed carboxylic groups and release them from the rock surface by replacing surface-carboxylate bonds. The carboxylic groups belong to organic acids presented in the oil. When the bonds are broken, the oil is detached from the surface and may be further produced. If the attached carboxylic groups belong to a layer of heavy hydrocarbons adsorbed on the surface, their detachment may result in a more water-wet surface.

Unlike $\mathrm{Ca}^{2+}$ functioning at any temperature, $\mathrm{Mg}^{2+}$ comes into play at high temperatures: $\mathrm{Mg}^{2+}$ may displace a Ca-carboxylate complex from the surface. Eqs (1) and (2) demonstrate this reaction (Zhang et al. 2007):

$$
\begin{aligned}
& 2 \mathrm{CaCO}_{3}+\mathrm{Mg}^{2+}=\mathrm{CaMg}\left(\mathrm{CO}_{3}\right)_{2}+\mathrm{Ca}^{2+} \\
& \mathrm{Ca}^{2+}+\mathrm{R}-\mathrm{COOH} \rightarrow \text { Oil recovery }
\end{aligned}
$$

Interplay between the potential determining ions (PDI), e.g. $\mathrm{Ca}^{2+}, \mathrm{Mg}^{2+}$ and $\mathrm{SO}_{4}{ }^{2-}$, is an important factor for this recovery mechanism. Numerous experiments were performed to verify the roles of these ions, in order to maximize performance of the waterflooding under particular 
conditions. Often, the ion exchange was not directly observed; instead, additional oil recovery from imbibition and core flooding experiments using the PDI containing brines was regarded as an indicator for the process.

First, it was noticed that a higher $\mathrm{SO}_{4}{ }^{2-}$ concentration is beneficial for oil production. Zhang and Austad (2006) performed spontaneous imbibition experiments with an outcrop chalk at various temperatures. The concentration of $\mathrm{SO}_{4}{ }^{2-}$ in the imbibing brine varied between 0 and 4 times of its concentration in seawater, while the $\mathrm{Ca}^{2+}$ concentration was kept constant, equal to concentration in seawater. It was observed that oil recovery increased substantially with increasing $\mathrm{SO}_{4}{ }^{2-}$ concentration. Similar observations was made by Strand et al. (2006a), where a significant increase in oil recovery was achieved by three-times increasing the $\mathrm{SO}_{4}{ }^{2-}$ concentration in the imbibing seawater. Puntervold et al. (2015) reported a $10 \%$ additional recovery in the imbibition experiments by spiking 3-4 times $\mathrm{SO}_{4}{ }^{2-}$ concentration in the $\mathrm{NaCl}$ depleted seawater.

Core flooding experiments with Stevns Klint chalk confirmed the effectiveness of $\mathrm{SO}_{4}{ }^{2-}$ (Zahid et al., 2010). A slight yet definite (3-5\%) additional oil recovery was obtained by injecting seawater or seawater with a three times increased $\mathrm{SO}_{4}{ }^{2-}$ concentration in both secondary and tertiary modes. However, this effect was not observed for a reservoir rock (see the discussion below).

The effect of $\mathrm{Ca}^{2+}$ and $\mathrm{Mg}^{2+}$ was also studied in the imbibition experiments (Zhang et al., 2007, 2006; Zhang and Austad, 2006). The oil recovery increased consistently with the increase of the $\mathrm{Ca}^{2+}$ concentration, while the $\mathrm{SO}_{4}{ }^{2-}$ concentration was kept constant in the imbibing brine. In addition, when $\mathrm{Mg}^{2+}$ or $\mathrm{Ca}^{2+}$ were added into the imbibing brine, which was initially free of them, the oil recovery increased significantly.

Co-existence of $\mathrm{Mg}^{2+}$ and $\mathrm{SO}_{4}{ }^{2-}$ was found to be crucial for this mechanism. Karoussi and Hamouda (2007) reported increased oil recovery from the Stevns Klint chalk by imbibition experiments with the brines containing $\mathrm{Mg}^{2+}$ and $\mathrm{SO}_{4}{ }^{2-}$. Similar results were observed with limestone cores by Karimi et al. (2016). It was found that injection of the $\mathrm{Mg}^{2+}$ and $\mathrm{SO}_{4}{ }^{2-}$ containing brine may result in higher imbibition, and that the brines containing both $\mathrm{Mg}^{2+}$ and $\mathrm{SO}_{4}{ }^{2-}$ are more efficient than only the $\mathrm{Mg}^{2+}$ containing brine.

However, despite the numerous evidences of the beneficial effects of PDIs, negative results were also reported. After secondary recovery by injecting single component brines $\left(\mathrm{NaCl}, \mathrm{MgCl}_{2}\right.$, $\mathrm{Na}_{2} \mathrm{SO}_{4}, \mathrm{MgSO}_{4}, \mathrm{CaCl}_{2}$ ), Gandomkar and Rahimpour (2015) did not observe any additional oil recovery by seawater or formation water injection into reservoir limestone cores.

In some cases, the smart water effect was observed even if PDIs were selectively removed or displaced. Gupta et al. (2011) obtained additional oil recovery by applying the $\mathrm{SO}_{4}{ }^{2-}$ depleted seawater. Adding borate and phosphate into such a brine increased further the oil recovery. 


\section{Temperature dependence}

The ion exchange process discussed above appears to be temperature dependent. Since the mechanism involves exchange of the $\mathrm{Ca}^{2+}$ ion from a rock by the $\mathrm{Mg}^{2+}$ from a brine, this may detected by measurements of the ion concentrations in the effluent in the course of the flooding experiments.

The exchange becomes more effective at higher temperatures (Zhang et al., 2007). The $\mathrm{Ca}^{2+}$ concentrations in the effluent at different temperatures were analyzed in that work. There was no detectable increase of $\mathrm{Ca}^{2+}$ concentration at $23^{\circ} \mathrm{C}$ and $70^{\circ} \mathrm{C}$, while the increase of about $20 \%$ and $40-50 \%$ was observed at $100^{\circ} \mathrm{C}$ and $130^{\circ} \mathrm{C}$, correspondingly. The temperature of $70^{\circ} \mathrm{C}$ was found to be the lowest threshold for the Ca-Mg exchange to take place (Austad, 2013).

The affinity of $\mathrm{Ca}^{2+}, \mathrm{Mg}^{2+}$, and $\mathrm{SO}_{4}{ }^{2-}$ toward the limestone surface was evaluated for a range of temperatures, from the room temperature to $130^{\circ} \mathrm{C}$. It was observed that $\mathrm{Mg}^{2+}$ adsorbed stronger at higher temperatures. Similar results were obtained for a chalk surface (Strand et al., 2008). The observations were explained by the level of hydration of $\mathrm{Mg}^{2+}$ and $\mathrm{SO}_{4}{ }^{2-}$. At low temperatures $\mathrm{SO}_{4}{ }^{2-}$ and $\mathrm{Mg}^{2+}$ are strongly hydrated. If the temperature rises above $100^{\circ} \mathrm{C}$, the degree of hydration decreases, so that $\mathrm{Mg}^{2+}$ and $\mathrm{SO}_{4}{ }^{2-}$ are easier to adsorb on the chalk surface.

The effect of the temperature dependence of the ion exchange process on oil recovery was studied by the imbibition and core flooding experiments (Zhang et al., 2007; Zhang and Austad, 2006). A substantial increase of oil recovery was observed upon increasing temperature from 40 to 70,100 and $130{ }^{\circ} \mathrm{C}$ in the imbibition experiments with the PDI containing brines. The same tendency was also observed when the brines containing only single PDI were injected (in the brines containing $\mathrm{MgCl}_{2}$ or $\mathrm{Na}_{2} \mathrm{SO}_{4}$ ). Fathi et al. (2011) observed a significant increase of oil recovery with the increase of temperature by injecting a seawater depleted by $\mathrm{NaCl}$, but spiked with 4 times of $\mathrm{SO}_{4}{ }^{2-}$ or $\mathrm{Ca}^{2+}$ concentration.

However, the impact of temperature is less significant in the core flooding experiments. Zahid et al. (2012b) observed increase of oil recovery by injection of seawater into the Stevns Klint and North Sea chalk plugs. The additional recovery ranged from $1.1 \%$ at $40{ }^{\circ} \mathrm{C}$ to $4.4 \%$ at $120{ }^{\circ} \mathrm{C}$, which is a rather small increase compared to the imbibition experiments.

\section{Effect of a rock type}

In many experiments described above, the outcrop chalk from Stevns Klint was used as an analog for North Sea reservoir chalk. However, regarding the mechanism of surface ion exchange, it may not be representative for the reservoir rocks. The researchers reported different reaction, under similar experimental conditions, of the outcrop and reservoir chalk on smart waterflooding, as well as from the outcrops of a different origin. Zhang et al. (2007) pointed out that the ion exchange mechanism is difficult to be extended to limestone reservoir rock, since the reactivity of biogenic chalk is much higher than of the recrystallized limestone. 
Romanuka et al. (2012) performed a series of imbibition experiments with the Stevns Klint chalk, limestone cores, and dolomite cores. Only the Stevns Klint chalk exhibited higher recovery with the increased sulfate concentration, while for other cores additional recovery was obtained by injection of a low salinity brine. The authors speculated that, apart from chemical composition of the rock, other properties (e.g. structure of the pore space) may affect the recovery. Similar observations regarding sulfate were reported by Zahid et al. (2012): injection of seawater with a high $\mathrm{SO}_{4}{ }^{2-}$ content resulted in a substantial additional recovery from the Stevns Klint chalk, while no response was observed for a North Sea reservoir chalk.

The effect of low salinity flooding was also different depending on a particular rock. A number of researchers reported successful application of the low salinity flooding in the Middle East limestone reservoir rock (Mohsenzadeh et al., 2016; Yousef et al., 2012b, 2011, 2010; Zhang and Sarma, 2012). However, no additional recovery was obtained when flooding an Aalborg outcrop core (Zahid et al., 2012b). Austad et al. (2012) pointed out that anhydrite must be present in the rock matrix in order to obtain the low salinity effect. Dissolution of anhydrite by injection of low salinity brine could produce $\mathrm{SO}_{4}{ }^{2-}$ and $\mathrm{Ca}^{2+}$ in situ, which facilitates surface ion exchange. They performed core flooding experiments with limestone cores from the aqueous zone of a reservoir. A small amount of additional recovery (1\% to 5\% OOIP) was obtained by low salinity flooding, in association with anhydrite dissolution. Shehata et al. (2014) performed corefloods on Indiana limestone core samples. No additional oil was produced after injection of the diluted seawater, while presence of potential determining ions resulted in additional production, similar to the Stevns Klint core flooding. Finally, Alameri et al. (2014) described flooding experiments in a Middle East rock, where both low salinity and PDIs produced additional effect. In general, the results presented in the different works look controversial and cannot be interpreted as an evidence in favor or against a single production mechanism.

Behavior of the dolomite rock regarding smart waterflooding was also examined. Mahani et al. (2015) carried out the contact angle and the Zeta potential measurements with a dolomite outcrop and a limestone reservoir rock from Middle East. When exposed to diluted seawater, the contact angle on the dolomite surface exhibited an insignificant change compared to the limestone. The dolomite exhibited also a higher zeta potential for all the tested brines (e.g. formation water, seawater, 25 times diluted seawater), which is not favorable for desorption of hydrocarbons. This conclusion was strengthened by Gachuz-muro and Sohrabi (2017). Core flooding experiments were performed with a dolomite core plug, and no additional recovery was observed under injection of seawater or diluted seawater.

\section{Discussion}

It is evident from the numerous reported observations that the surface ion exchange is one of the mechanisms behind smart waterflooding, or, at least, accompanying it. However, in order to benefit from such a mechanism, some conditions should be met. For some rocks, temperature should be higher than a certain threshold value to maximize the extend of the reaction, so that the effect becomes significant enough to produce residual oil. From the aspect of chemical kinetics 
in general, the extent of a reaction is always related to the concentrations of the reactants. Hence, it can be speculated that the threshold value of the temperature should be dependent on the composition of the brine. However, this has not been verified yet.

As discussed above, the mechanism is not universal, and depends on the rock lithology. A general trend is that the biogenic outcrop chalk, which has undergone less re-crystallization process than dolomite and limestone, is more responsive to the surface ion exchange. Other types of carbonate rock are more inert toward this mechanism. The different ions may behave differently in the different rocks, even with very close mineralogies. As remarked by Romanuka et al. (2012), other properties of the rock may also be important. In other words, surface ion exchange may not be the sole mechanism responsible for additional recovery under smart waterflooding.

\subsubsection{Surface charge alteration}

\section{Basic concepts}

The surfaces of solids are usually charged. For example in the case of positive charge, a layer of negative charges is accumulated in the solution at some distance from the surface. Additional positive and negative layers may also appear. This distribution of the ions is efficiently described by a double layer, characterized by thickness and potential difference (the so-called zetapotential). If another surface is introduced in a vicinity of solid, it may be repelled, with the repulsive force characterized by a value of disjoining pressure. In particular, an oil surface near a solid in a brine environment may be considered. A larger thickness of the double layer, a higher disjoining pressure, or a negative value of the zeta-potential means that the oil is repelled from the solid surface and becomes easier to produce.

Hirasaki (1991) proposed a model of surface forces between water, oil and mineral surface, which includes electrostatic, van der Waals, and structural components. According to the model, a thin water film is present between the oil and mineral surfaces. The total effect of the forces acting in this system is expressed as a disjoining pressure isotherm. Its integral gives the specific interaction potential isotherm which can be used to determine stability of the water film at a three phase contact region. A higher disjoining pressure indicates the stable water film and vice versa.

The disjoining pressure is affected by the surface potential and thickness of the electrical double layer (EDL) (Hiorth et al., 2010). If the charges of both oil and the mineral surfaces are of the same sign, the water film will be stable, and the surface will be water-wet. Otherwise the water film will collapse and the surface will become oil-wet. On the other hand, the thicker the EDL, the higher the electrostatic force, hence the higher the disjoining pressure, and vice versa.

Distribution of the charges near the solid surface may be evaluated on the basis of the DLVO model (Derjaguin and Landau, 1941; Elimelech et al., 1998; Verwey and Overbeek, 1948). This theory describes repulsive or attractive forces between charged surfaces or colloidal particles in an electrolyte solution. Figure 1 shows a characteristic distribution of the electrostatic potential 
and the DLVO force between a negatively charged particle and a negatively charged infinite plane in an electrolyte solution.

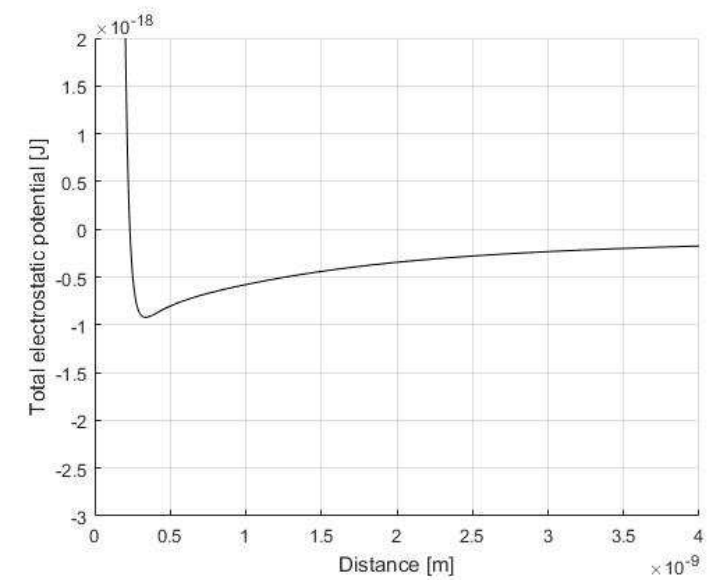

(a)

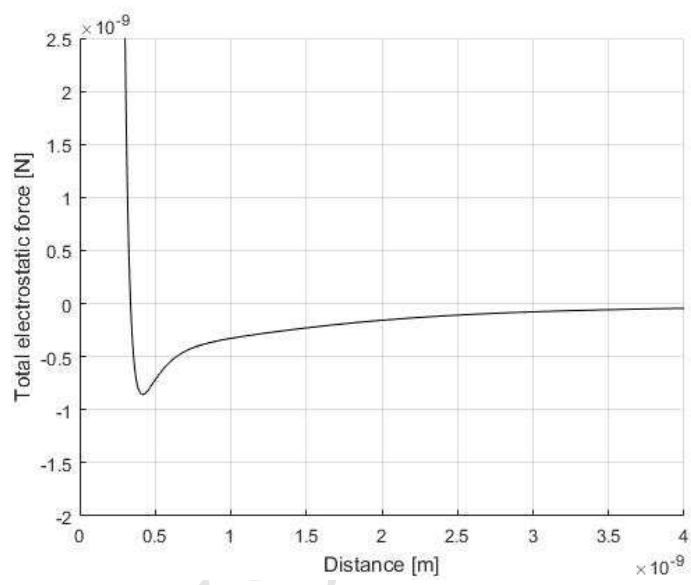

(b)

Figure 1. DLVO forces (a) energy potential between a particle and a surface as a function of distance; (b) force between the particle and surface as a function of distance.

Alshakhs and Kovscek (2016) demonstrated application of the DLVO in order to evaluate the effect of divalent ions in carbonates. In this study, zeta potential data were used to predict contact angles and disjoining pressures by the DLVO theory. Close agreement between the experimental and the simulation results was reported.

\section{Zeta potential}

The oil may be attached to the surface of a rock by carboxylic groups belonging to the heavy oil components. Since the carboxylic groups are negatively charged, a negative value of zeta potential on mineral surface is preferred to reduce adsorption of oil. This value means that negative ions from the solution accumulate near the positively charged surface, repelling the oil.

Several factors may increase negative charge of the mineral surface. It was reported that injection of diluted seawater resulted in a more negative zeta potential of carbonate rock than of seawater and formation water, which produces the change in surface charge and increases oil recovery (Mahani et al., 2015; Yousef et al., 2012b). Increase in temperature from 40 to $60{ }^{\circ} \mathrm{C}$ leaded to a more negative surface charge (Yousef et al., 2012b). It was also reported by Zhang and Austad, 2006, that a higher $\mathrm{SO}_{4}{ }^{2-} / \mathrm{Ca}^{2+}$ ratio lowers the zeta potential, corresponding to increase of the oil recovery under water imbibition.

Karoussi and Hamouda (2007) calculated disjoining pressure for several calcite-oil-water systems with the aqueous phase being distilled water, $0.1 \mathrm{M} \mathrm{Na}_{2} \mathrm{SO}_{4}$, or $0.1 \mathrm{M} \mathrm{MgCl}_{2}$ solution. A significant increase of disjoining pressure was observed for the $0.1 \mathrm{M} \mathrm{MgCl}_{2}$ solution. The imbibition experiments also showed increased recovery when applying this solution. Alshakhs and Kovscek (2016) calculated the disjoining pressure between the oil and rock surfaces in brine 
environments for various brine compositions. The most stable water film was found when applying the diluted $\mathrm{MgSO}_{4}$ brine.

Mahani et al. (2015) measured both zeta potentials and contact angles with limestone and dolomite samples. It was reported that under application of a low salinity brine the zeta potential of the limestone becomes more negative. This is consistent with the results of contact angle measurements, which showed that the limestone surface is less oil-wet when exposed to a low salinity brine. But low salinity has much less effect on dolomite. Due to different values of the zeta potential, the adhesion forces between oil and dolomite are stronger. This was confirmed in the contact angle measurements. It was concluded that the change of surface charge was the primary mechanism in low salinity water flooding.

\section{Effect of non-potential determining ions}

Fathi et al. $(2010,2011)$ observed that not only compositions of the active ions $\mathrm{Ca}^{2+}, \mathrm{Mg}^{2+}$, and $\mathrm{SO}_{4}{ }^{2}$, but also an amount of the non-active salt, $\mathrm{NaCl}$, is important in oil recovery from carbonates. If the ionic double layer near a positively charged calcite surface contains less amount of a non-active salt, such as $\mathrm{NaCl}$, access of sulfate to the calcite surface increases. In this way, sulfate, which is the key ion to change wettability of a rock surface, can act more efficiently in the absence of non-active ions.

Although it is mentioned in some works that monovalent ions like $\mathrm{Na}^{+}$and $\mathrm{Cl}^{-}$are among the non-active ions, this may be not that definite. Depletion of seawater from $\mathrm{NaCl}$ causes significant reduction in salinity, which may produce additional effects. Alameri et al. (2014) removed $\mathrm{NaCl}$ from the injection water and concluded that oil recovery increased by $8 \%$. A proposed explanation was expansion of the electrical double layer, which can be a sign of the low salinity effect, but not of the inactivity of the removed ions.

\section{Effect of $\mathrm{pH}$}

One of the important parameters affecting electrostatic interactions between the three phases: oil, brine and carbonate surface, is $\mathrm{pH}$ (Sohal et al., 2016). Calcite is normally charged positively at neutral $\mathrm{pH}$. However, it can become negatively charged at higher values of $\mathrm{pH}$ (Hirasaki and Zhang, 2004). In particular, application of alkali changes positive surface charge of the calcite during imbibition by alkaline-surfactant solutions (Hirasaki and Zhang, 2004).

Buckley et al. (1989) determined the conditions, under which various crude oils adhere to a solid surface at different $\mathrm{pH}$ and ionic strengths of the brine. They reported reduction of the zetapotential by discreteness effect of dissociated groups at the interface at higher $\mathrm{pH}$.

Somasundaran and Agar (1967) investigated the zero point of charge (ZPC) as a function of pH. The values of ZPC lied within the range of $\mathrm{pH}$ from 8 to 9.5 . The zeta potential, $\mathrm{pH}, \mathrm{Ca}^{2+}$ and $\mathrm{CO}_{3}{ }^{2-}$ concentrations in the system were measured periodically. When $\mathrm{pH}$ in the solution was more basic, the surface was negatively charged, since negative ions predominated at the 
interface. For a more acidic $\mathrm{pH}$, the surface was positively charged. It was suggested that $\mathrm{Ca}^{2+}$, $\mathrm{HCO}_{3}{ }^{2-}, \mathrm{H}^{+}, \mathrm{OH}^{-}$and $\mathrm{CO}_{3}{ }^{2-}$ become the potential-determining ions at the values of $\mathrm{pH}$ above 9.

\section{Interaction between the double layer and the surface complexation}

Some recent studies involving surface complexation modelling (SCM) indicated relationships between the charge of a double layer and wettability of the minerals. The surface complexation models describe preferential sorption of the ions on the charged surfaces. Song et al. (2017) proposed a SCM based on a generalized double layer model. The SCM model was developed to predict zeta potentials of a synthetic calcite surface in brines containing various potential determining ions $\left(\mathrm{Mg}^{2+}, \mathrm{Ca}^{2+}, \mathrm{SO}_{4}{ }^{2-}\right.$ and $\left.\mathrm{CO}_{3}{ }^{2-}\right)$ under different $\mathrm{CO}_{2}$ partial pressures. The model was fitted to measured zeta potential data. It was found that synthetic calcite exhibited positive zeta potentials in brines containing $\mathrm{Ca}^{2+}$ or $\mathrm{Mg}^{2+}$. The zeta potential can shift from positive to negative when increasing $\mathrm{CO}_{3}{ }^{2-}$ or $\mathrm{SO}_{4}{ }^{2-}$ concentrations at a partial pressure of $\mathrm{CO}_{2}$ equal to $10^{-}$

${ }^{3.4} \mathrm{~atm}$. However, at a partial pressure of $1 \mathrm{~atm}$ the zeta potential did not become negative, even if the brine contained $0.1 \mathrm{M} \mathrm{CO}_{3}{ }^{2-}$ or $\mathrm{SO}_{4}{ }^{2-}$.

Another study by Erzuah et al. (2017) explained how the surface charge affects wettability of calcite by hydrocarbon adhesion. The authors constructed a surface complexation model with the PHREEQ-C software, in order to estimate the wettability of quartz, kaolinite and calcite. Validity of the model was confirmed by the wettability estimation by the floatation method. It was concluded that the surface charge of a mineral has a dominant effect on the oil adhesion, rather than the properties of the brine/oil interface. For a positively charged mineral, like calcite, the carboxylic acid components in the oil are more effective, than its basic counterparts, in changing wettability of the mineral through adhesion.

Yutkin et al. (2016) studied the calcite/brine bulk kinetics and equilibria, as well as the calcite/brine surface equilibria with an ion comlexation model. It was pointed out that the double layer expansion is not possible unless the ionic strength is lower than $0.1 \mathrm{M}$. The rock dissolution cannot be a LSW mechanism because of the rapid rock/brine equilibration (carbonate could rapidly equilibrate with a brine in a short distance). The fines mobilization cannot occur because there is low clay content and low amounts of loose fines in the carbonate rocks studied by these authors. LSW cannot work as an alkaline flood because all the injected base will be consumed by carbonate dissolution near the wellbore and the $\mathrm{pH}$ will substantially decrease. The surface ion exchange remains a possible LSW mechanism, but, according to Yutkin et al., this is still unproven.

\section{Discussion}

As discussed in this section, expansion of double layer, higher disjoining pressure, or negative values of zeta potential can be reached at higher $\mathrm{pH}$ and lower salinities. This results in detachment of an oil from a solid surface and production of the residual oil. The zeta potential is used as an indicator for variation of the surface charge. 
Measurement of zeta potential at different $\mathrm{pH}$ and calculation of disjoining pressure are often accompanied with uncertainties, especially, when measured in situ. Generally, there is a correlation between values of zeta potential and recoveries under the imbibition tests. However, this correlation is incomplete. Sometimes, inconsistency between the zeta potential data and the oil recovery is observed (Zhang et al., 2006). In the presence of magnesium, positive zeta potentials were observed; moreover, the potential increased by increasing the solution molarity. However, more oil was produced in the core flooding experiments. Yousef et al. (2012) reported that dilution of the injected seawater results in a more negative zeta potential. However, no additional oil was produced.

Hiorth et al. (2010) pointed out that alteration of the surface potential alone cannot explain the observed changes in oil recovery caused by changes in the water chemistry and temperature. The same is related to zeta potential: although it seems to be an important factor, it is insufficient for explanation of the recovery enhancement observed under smart waterflooding.

\subsubsection{Mineral dissolution}

Mineral dissolution, including calcite, dolomite and anhydrate, is one of the smart waterflooding mechanisms introduced in the literature. Dissolution of these species results in different effects, but some similarities are observed as well.

\section{Observations of the dissolution}

The calcite dissolution in a diluted brine occurs due to the following chemical reactions:

$$
\begin{aligned}
& \mathrm{CaCO}_{3} \Leftrightarrow \mathrm{Ca}^{2+}+\mathrm{CO}_{3}{ }^{2-} \\
& \mathrm{CO}_{3}{ }^{2-}+\mathrm{H}_{2} \mathrm{O} \Leftrightarrow \mathrm{HCO}_{3}{ }^{-}+\mathrm{OH}^{-}
\end{aligned}
$$

Additionally to calcite, dissolution/precipitation of magnesite and sulfate may take place (eqs. 3 and, correspondingly) (Alexeev, 2015):

$$
\begin{aligned}
& \operatorname{MgCO}_{3}(s)+H^{+} \Leftrightarrow \mathrm{Mg}^{2+}+\mathrm{HCO}_{3}{ }^{-} \\
& \mathrm{CaSO}_{4}(s)+H^{+} \Leftrightarrow \mathrm{Ca}^{2+}+\mathrm{SO}_{4}{ }^{2-}
\end{aligned}
$$

These reactions show that the calcite dissolution causes $\mathrm{pH}$ alteration (Lager et al., 2008a). Thus, increase in $\mathrm{pH}$ and $\mathrm{Ca}^{2+}$ concentration in the effluent during oil recovery may indicate that the dissolution happens. Hamouda and Maevskiy (2014) observed increase of the $\mathrm{Ca}^{2+}$ concentration in the effluent, which was attributed to the chalk dissolution. They suggested $\mathrm{Ca}^{2+} / \mathrm{Mg}^{2+}$ ion exchange and rock dissolution to be the main recovery mechanisms. Higher calcium and lower magnesium concentration in the effluent in comparison to the injection fluid was observed when 
injecting the diluted brines. However, Mahani et al. (2015) pointed out that the surface charge variation is a primary mechanism, while rock dissolution is a secondary reason for enhancement of the oil recovery. Additional oil recovery was observed under injection of $\mathrm{CaCO}_{3}$ saturated seawater, where the calcite dissolution was excluded.

Mohammadkhani et al. (2018) investigated the effect of connate water salinity and saturation, as well as of the injected brine salinity, by conducting five core floodings on limestone core plugs at the room temperature. It was concluded that de-dolomitization and anhydride precipitation were among the determining mechanisms. The rock dissolution, indicated by increased $\mathrm{pH}$, was only observed at tertiary stage, under injection of very low salinity seawater $(<3000 \mathrm{ppm})$.

\section{Production mechanisms related to mineral dissolution}

The mineral dissolution may facilitate oil production in several ways. Permeability modification is its one benefit. Gachuz-muro and Sohrabi (2017) injected the 50 times diluted seawater into a dolomite core in the tertiary recovery mode. A certain increase in permeability was observed along with a slightly higher oil recovery. The change in permeability was attributed to rock dissolution, which was verified by increase of the calcium and bicarbonate concentrations in the collected effluent.

Hiorth et al. (2010) constructed a chemical model to study surface charge and rock dissolution in a pure calcium carbonate rock. Numerous experimental data were used to tune the model. It was found that calcite dissolution matches well with the observed chemical and temperature dependences. It appeared to be a controlling factor for the observed smart water effect. The oil adsorbed on the calcium carbonate surface may be released due to its dissolution. Then surface that has formed after dissolution and oil release becomes water-wet.

Yousef et al. (2010, 2012) performed NMR measurements for a Middle East reservoir core before and after low salinity flooding. The results showed improved connectivity between macro- and micropores due to dissolution of the rock material in small pores, which is beneficial to improve sweep efficiency of the water flooding.

Karimi et al. (2016) described the rock dissolution in connection with the electric double layer interactions. The calcite dissolution results in an increased $\mathrm{pH}$, which creates a more negatively charged brine/rock interface, which is repelled by a negatively charged brine/oil interface.

Dissolution of anhydrate was suggested to be able to promote wettability alteration by producing $\mathrm{Ca}^{2+}$ and $\mathrm{SO}_{4}{ }^{2-}$ in-situ. Then it is related to the multi-ion exchange process and, subsequently, to release of the oil from the surface. This factor is often associated with injection of a low salinity brine (Austad et al., 2012; Chandrasekhar and Mohanty, 2013). Yousef et al. (2012) detected anhydrite dissolution by analyzing $\mathrm{SO}_{4}{ }^{2-}$ concentration during low salinity injection. It was pointed out that presence of the anhydrite is a key factor for low salinity injection, since its dissolution could produce in situ the potential deterimining ion $\mathrm{SO}_{4}{ }^{2-}$ (Austad et al., 2015, 2012). 
Alshakhs and Kovscek (2016) confirmed this mechanism and suggested that mineral dissolution supplied more divalent ions during flooding.

$\mathrm{pH}$ alteration may also occur under dissolution of calcite. Increase of $\mathrm{pH}$ may have a positive effect on the emulsion formation, as will be discussed in section 3.4. On the other hand, dissolution of calcite may occur mainly in the water filled part of the porous space, increasing mobility of the water compared to oil (although, to the best of our knowledge, the extent of this effect has not been studied).

\section{Dynamics of dissolution}

The mineral dissolution or precipitation is a static effect, according to our classification: It appears even if there is no flow. From the practical point of view, however, it is important to find out how this effect will manifest itself when coupled with the flow characteristic of reservoir development or laboratory flooding experiments (Houston et al., 2006). Such a study has been carried out by Alexeev et al., (2015), following and extending previous similar works (as applied to other processes) (Aharonov and Spiegelman, 1997; P. Bedrikovetsky et al., 2009; P. G. Bedrikovetsky et al., 2009; Lam et al., 2008; Rubin, 1983; Spivey et al., 2004).

By extended numerical simulations it was found that the most important parameter is the ratio of the characteristic time of the dissolution reaction to the flow time. The last time may be chosen, for example, to be a time necessary for injection of one porous volume. If the time ratio is high (the dissolution is slow), then the effect of dissolution is insignificant, almost uniform, and occurs only after many porous volumes injected. As opposite, fast dissolution appears only close to the injection spot, without spreading deeply into the rock. As injection proceeds, porosity in a zone close to the injection spot increases, while the rest of the reservoir (or laboratory core) remains almost intact. In the extreme cases of fast reactions and many porous volumes injected, structures like wormholes may be formed.

Another observed effect is related to non-additivity of the volumes under dissolution. When the rock is dissolved in brine, the total volume usually decreases. The negative volume excess may rather significant, up to 0.8 of the initial rock volume. In dynamics, this results in a slight acceleration of the oil displacement by brine.

\subsection{Other mechanisms}

2.2.1 Interfacial tension, reology, and liquid-liquid interactions

Interfacial tension (IFT) measurements for smart waterflooding were conducted by many researchers (Al-Attar et al., 2013; Mahani et al., 2015; Yousef et al., 2012b). In particular, Khaksar Manshad et al. (2016) measured IFT of various ionic brines at a high temperature and atmospheric pressure. It was found that the $\mathrm{K}_{2} \mathrm{SO}_{4}$ solution at $2000 \mathrm{ppm}$ produces the lowest IFT out of all the tested brines. However, in all the studies above, reduction of the IFT was too small to have an impact on oil recovery.

Sheng et al. (2010) pointed out that IFT plays a very important role with or without wettability alteration, during the entire process of flooding. On the contrary, Yousef et al. $(2010,2011)$ 
investigated the impact of salinity and ionic composition of injection water on oil recovery from carbonate reservoir cores. Interfacial tensions between the reservoir live oil and the field connate water, the seawater, and it's different dilutions were measured. The results showed that smart water flooding has an impact on the contact angle rather than IFT. This implies that diluted seawater influences rock/oil/brine rather than oil/brine interactions.

In some cases, even reverse effect of low salinity water on IFT was observed. An increase in IFT with decreasing salinity was reported by Alameri et al. (2014), in contradiction with improvement of the oil recovery by the low salinity effect.

Some studies pointed out that qualitative modification of an oil-water interface may be more important than just variation of the interfacial tension (Ayirala et al., 2017a, 2017b; Varadaraj and Brons, 2012). Depending on compositions of the contacting fluids, the interface may be viscous (liquid-like) or elastic (solid-like); the intermediate states are also possible. This effect is known for at least 60 years for oil-brine contacts (Criddle and Meader, 1955). It was attributed to the presence of surface-active compounds in oil, particularly, to asphaltenes (Hasiba and Jessen, 1966; Sheu et al., 1995; Varadaraj and Brons, 2012).

Recently it has been realized that the mentioned studies are important for smart waterflooding. If an oil-brine interface becomes solid-like, oil separates easier from the rock surface. On the contrary, if the interface is liquid-like, separate oil drops are easier to coalesce and to form a continuous flowing oil phase. Thus, in the "ideal brine recipe", the ions increasing the elasticity of the oil-water interface should concentrate near the rock surface, while the ions making the interface more viscous should stay in the solution. Particularly, presence of sulfates in a brine promotes in some cases hardening of the interface (Ayirala et al., 2017a, 2017b).

\subsubsection{Oil viscosity reduction}

It has been reported that interactions between oil and brine may affect the oil viscosity. This effect may be combined with the effect of a high temperature, usually resulting in the viscosity decrease.

Gachuz-muro et al. (2016) examined a crude oil after contact with a sweetened and diluted seawater. It was concluded that the structure of the crude oil varies in contact with the different brines. In another work Gachuz-muro et al. (2013) put an oil and a brine in contact, with a volume ratio of 1:4 (20\% oil and $80 \%$ brine) and measured viscosity of the oil before and after the contact. Normal brine (NW), distilled water (DW), formation water (FW) and a synthetic seawater (SW) corresponding to the Gulf of Mexico seawater were studied. Oil viscosity was reduced for all the tested brines, for the temperatures under $60{ }^{\circ} \mathrm{C}$, while after this point the trend was reversed. It was also observed that viscosity was reduced more if it was initially higher.

Zahid et al. (2012) measured viscosity of a Latin American oil, a Middle East oil, and heptane, after their interaction with seawater under different $\mathrm{SO}_{4}{ }^{2-}$ concentrations, under high temperature and pressure. Emulsification of these oils with a $\mathrm{SO}_{4}{ }^{2-}$ spiked seawater was also studied in this 
work. It was observed that viscosity was affected for the oils containing heavy components, while emulsification was detected for the oils where such components were not present in significant amounts. The mechanism of viscosity reduction was explained by association or dissociation of the heavy molecules upon variation of ionic components of the brine in contact. Variation of the viscosity could not be explained by emulsification, since it was higher for other oils involved in the study.

\subsubsection{Compaction}

Compaction due to the rock weakening has been considered as one of the mechanisms of additional recovery. To the best of our knowledge, however, only few studies relate compaction to smart waterflooding (Katika et al., 2018). Meanwhile, the connection is obvious, since injection of an incompatible brine might result in chalk weakening. Shrinking of the pore space results in the oil squeezing out of it. Here we provide a short overview of the field observations and recovery mechanisms under reservoir compaction.

Compaction is classified as a static mechanism, since it may be, and usually is, measured in the laboratory experiments not involving liquid flow (saturation of a rock sample by brine with subsequent compression). On the other hand, selective compaction may result in fluid diversion, which is a purely dynamic effect. This is a particular case of contribution of the rock heterogeneity, which will be discussed further.

\section{Field observations}

Seafloor subsidence was observed in North Sea chalk reservoirs in 1980s after their development in early 1970s (Boade et al., 1989; Ruddy et al., 1989; Sylte et al., 1999). More than 7.8 meters of seafloor subsidence was detected in the Ekofisk field at the Norwegian sector of the North Sea since its production from 1971. The subsidence was primarily considered to be a result of pressure depletion due to production. However, in 1994, the subsidence did not stop, although water injection was sufficient to stabilize reservoir pressure (Sylte et al., 1999). The North Sea Valhall chalk reservoir also demonstrated significant compaction and subsidence associated with reservoir pressure depletion (Ruddy et al., 1989).

\section{Reservoir compaction and oil recovery}

Observations of the reservoir compaction and seafloor subsidence in the North Sea triggered several research projects to study water weakening of chalk and reservoir compaction. Although reservoir compaction may lead to additional operation cost, it was demonstrated to be beneficial for hydrocarbon production (Boade et al., 1989; Ruddy et al., 1989; Sulak et al., 1991). A combination of experimental measurements and modelling tools was employed to study compaction. Ruddy et al. (1989) used experimentally determined rock compressibility of Valhall Chalk samples in a reservoir model. It was found that the chalk compaction provided a significant part of hydrocarbon recovery from the Valhall field. A similar procedure was applied to study the Ekofisk field. Sylte et al. (1999) measured the relationship between strain and porosity for the Ekofisk chalk. It was then used in a reservoir model to predict production and 
subsidence. The results showed that water weakening could add a significant amount of energy to the reservoir system, which facilitated oil production.

Reservoir simulations brought similar conclusions. Sulak et al., (1991) developed a modelling procedure to study reservoir compaction as a mechanism for hydrocarbon production in the Ekofisk field. It was concluded that reservoir compaction leads to increased production from the field. Boade et al. (1989) simulated compaction of the Ekofisk field by the ANSYS and DYNAFLOW simulators. It was found that waterflooding has a positive effect on compaction and subsidence. Chin and Thomas (1999) coupled a reservoir multiphase flow model with a geomechanical model and concluded that the water weakening effect may result in additional oil recovery, which may make a waterflood project more economically favorable for a watersensitive reservoir.

\section{Mechanisms of water weakening of chalk}

Several studies focused on the mechanisms of the water weakening of chalk. Johnson et al. (1986) performed uniaxial and hydrostatic tests on the Ekofisk chalk samples. The results revealed that a dominant mechanism of deformation is rotation and mechanical breakdown of coccolith fragments and other calcium carbonate grains of the chalk matrix. No obvious evidence was found for chemical processes, such as dissolution-reprecipitation of the carbonate material during compaction. Similar conclusions were reported later by Powell and Lovell (1994), who performed the SEM image analysis on North Sea chalk samples before and after compaction. It was concluded that a dominant mechanism is simple grain displacement, which is characterized by rotation and sliding of individual calcite grains. Chemically assisted compaction mechanisms such as pressure dissolution and stylolitization were found to be insignificant for the productioninduced compaction in the North Sea chalk.

However, more recent studies pointed out that chemistry of a saturating fluid plays an important role in the water weakening of chalk. By comparison of mechanical properties of the outcrop Lagerdorf chalk samples saturated with water and synthetic oil, Høeg et al. (2000) suggested that water-chalk interactions are governed by both capillary forces and chemical or physico-chemical processes.

Activity of water in the pore space may have an effect on mechanical strength of chalk (Risnes et al., 2005). Adsorption of the water molecules (which is a function of water activity) adds pressure on the grains. This pressure acts like a pore pressure and decreases cohesion of the chalk.

Calcite dissolution is another mechanism considered in the literature. Increased calcite solubility results in increased deformation rate (Hellmann et al., 2002). A study by Heggheim et al. (2004) showed 20 to $25 \%$ strength reduction for the cores saturated by seawater with an increased sulfate concentration, compared with the cores saturated by formation brine and seawater. The increased sulfate concentration was claimed to precipitate $\mathrm{Ca}^{2+}$ in a saturation fluid, which 
promoted dissolution of calcite. Dissolution of calcite and precipitation of $\mathrm{CaSO}_{4}$, rather than the capillary forces or water activity, was claimed to be responsible for weakening of the chalk.

A more complex mechanism involving ion adsorption and exchange was reported by Korsnes et al. (2008) and Austad et al. (2007). When a brine containing $\mathrm{Mg}^{2+}$ and $\mathrm{SO}_{4}{ }^{2-}$ is present in the pore space, $\mathrm{Mg}^{2+}$ substitutes $\mathrm{Ca}^{2+}$ at the grain contacts. $\mathrm{SO}_{4}{ }^{2-}$ acts as a catalyst in this process, by lowering down positive charge of the calcite surface. Hence, accessibility of $\mathrm{Mg}^{2+}$ to the surface increases. Different sizes of the $\mathrm{Ca}^{2+}$ and $\mathrm{Mg}^{2+}$ ions lead to structural changes in the inter-grain regions, which can weaken the chalk.

An effect of temperature on the water weakening of chalk was also studied by some researchers (Austad et al., 2007; Hellmann et al., 2002; Korsnes et al., 2008; Madland et al., 2002, 2006). However, contradictory conclusions were drawn. It was observed by Madland et al. (2002) that increased temperature from 20 to 130 degrees resulted, on average, in $20 \%$ reduction of yield and cohesion strength for water and glycol saturated chalk. Similarly, Hellmann et al. (2002) reported an increased strain with increased temperature during triaxial tests on water saturated chalk. On the contrary, it was reported by Korsnes et al. (2008) that hydrostatic yield stress was higher at 130 degrees than 90 degrees for chalk saturated by seawater and distilled water. Austad et al. (2007) also reported that water saturated chalk cores become stronger when temperature increases. A similar effect was observed for cores flooded with carbonated water (Madland et al., 2006).

Katika et al. (2018) observed that divalent ions contribute to the pore collapse in chalks, by weakening contacts between the grains. Nermoen et al. (2018) observed certain softening and weakening of chalk in sulfate rich brines. However, they concluded that neither presence of the certain ions in brine, temperature or aging alone are sufficient in order to predict chalk stiffness and strength. It is a combination of factors that determines elastic behavior of chalk.

\section{Discussion}

To the best of our knowledge, there are no studies indicating explicitly a relationship between smart water flooding, chalk compaction and oil recovery. However, there are links between them (Katika et al., 2018, 2015). It was widely reported in smart water projects that potential determining ions, mineral dissolution/precipitation, and temperature could have an impact on the oil recovery. The studies regarding water weakening of chalk involve similar parameters. It is shown that the potential determining ions have an impact on the mechanical properties of chalk. Although the reported effects are controversial, it may still be speculated that the following production mechanism takes place: Smart waterflooding reduces the strength of chalk; the weakened chalk undergoes enhanced compaction, which results in a change of pore structure and a decreased pore volume. Decrease of the pore space helps mobilizing stagnant oil. Verification of this mechanism is a subject for future research. 


\section{Dynamic mechanisms}

In this section, mechanisms of smart waterflooding dependent on flow are discussed. These mechanisms include heterogeneity and flow diversion, as well as fines production and emulsion formation.

\subsection{Flows dynamics and denuded zones}

Many experimental works referred above contain results of flooding experiments carried out in a regime of spontaneous imbibition. The imbibition is governed primarily by capillary forces. Hence, no wonder that wettability and properties of the oil-brine-rock interfaces have been reported to determine success of the smart waterflooding.

Meanwhile, the literature indicates a large difference between the results of the spontaneous imbibition experiments and forced displacement (Strand et al., 2008; Zhang et al., 2007). While the role of capillary forces may be significant in laboratory waterflooding experiments, on the large reservoir-scales it may be less important, and viscous forces may prevail over capillarity (Bedrikovetsky, 1993).

The flow dynamics under injection of a different salinity brine and prevailing viscous forces (forced displacement) is generally similar to the dynamics of chemical flooding (Bedrikovetsky, 1993; Zeinijahromi et al., 2011). A commonly used model is based on the classical BuckleyLeverett theory and its extensions (Bedrikovetsky, 1993; Pope, 1980). This theory predicts frontal character of displacement, with a residual oil being slowly produced after arrival of the water displacement front. A typical saturation profile is shown in Figure 2, a) (Alexeev, 2015). It should be noticed that the front of the displacing brine propagates always behind the oil displacement front. The reason is that the displacing brine fills a larger volume than oil, replacing both oil and the formation water.

Assume now that the injected brine contains a salt (or a chemical) affecting the recovery. The corresponding profiles of oil and brine saturations are schematically shown in Figure 2, b), for the case of tertiary injection. Due to the activity of the injected brine component, an additional oil bank is formed. Its production results, eventually, in decrease of the final oil saturation. If the injected chemical gets adsorbed (as most of them do), it travels behind the carrying brine. A zone of the so-called denuded water is formed. As a result, the effect of the injected brine on oil production is postponed. This delay may be even higher if the active component in the injected brine does not act instantaneously, but with a certain delay (reaction time). Then a positive effect of enhanced oil recovery may appear after many porous volumes injected. Additionally, the residual oil mobilized by the active component may travel with a different velocity than the "main" connected oil. This causes an extra delay (Alexeev, 2015). The whole picture of recovery is smeared, to a certain degree, by dispersion caused by heterogeneity of the rock, capillary forces, flow dispersion and reaction kinetics.

If the oil is produced in a regime of continuous secondary flooding, the active component (or the brine with a different salt composition) should appear after additional produced oil, like on the 
Figure 2. To the best of our knowledge, this has never been reported. Under tertiary recovery, additional oil production may sometimes happen simultaneously with the arrival of the injected additive (Alexeev, 2015).

Dispersion is responsible for mixing of the injected and connate brine, as experimentally studied by Graue et al. (2012). By nuclear-tracer imaging of the dynamic water saturation profiles, it has been verified that the mixing zone between the injected and the connate water is of a limited extent, and that, eventually, all the connate water becomes displaced by the injected brine (Graue et al., 2012) .

A system of flow equations describing all the physical mechanisms discussed above may only be solved numerically. Several attempts have been carried out to match available experimental data by solutions of such systems (Alexeev, 2015; Andersen et al., 2012; Eftekhari et al., 2017; Evje et al., 2009; Madland et al., 2011; Qiao et al., 2015). Complexity of the described process results in a relatively large number of adjustment parameters. It has been found that the resulting solutions can be fitted more or less accurately to experimental data, although Alexeev (2015) mentions that the concentration "tails" during long flooding experiments cannot be captured by the model. Fitting to the flooding data is necessary, and the flooding results cannot be predicted based on other experiments. This has been demonstrated by Eftekhari et al. (2017) by attempting to predict the flooding results, adjusting the reaction equilibria to data on independently measured zeta potentials. Especially, such a practically important parameter as residual oil saturation after flooding cannot be determined in advance and must be fitted every time to particular experimental data.

Alexeev (2015) and Eftekhari et al. (2017) indicated a correlation between the residual oil saturation and amounts of the adsorbed sulfate ions, while (contrary to the expectations) a correlation with concentrations of other potential determining ions is not that clear. This is confirmed by observations of Qiao et al. (2015), who account for mineralogy of the rock. In this study, it is shown that the recovery improvement is correlated with the amount of anhydrite, which is considered as a source for sulfate.

Another important observation is presence of the different characteristic time scales in the system, ranging from minutes to months (Alexeev, 2015; Andersen et al., 2012). Short-time transient behavior is better approximated by the rate-driven ion exchange on the surface, while long-time behavior is quasi-steady state on the laboratory scale. 


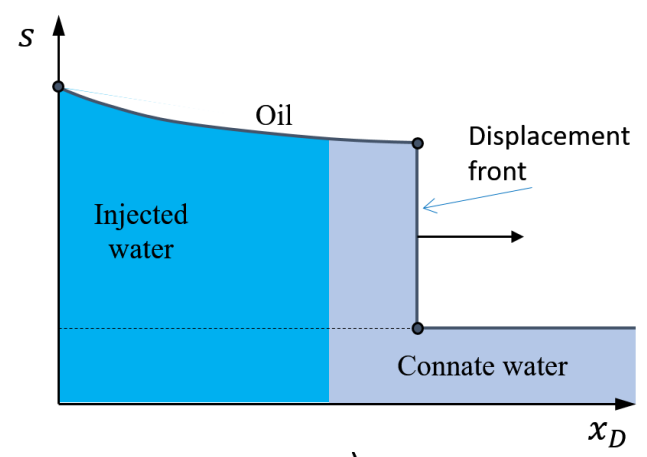

a)

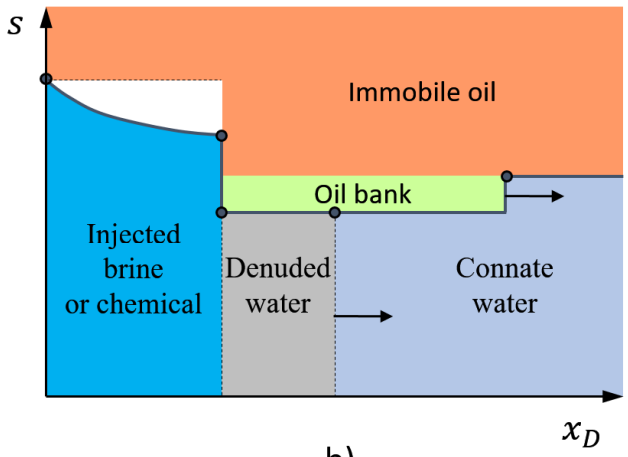

b)

Figure 2. a) Displacement of oil by brine in the Buckley-Leverrett theory; b) Displacement of the oil by a chemical solution in a tertiary mode (after A. Alexeev, 2015)

\subsection{Heterogeneity and fluid diversion}

Although heterogeneity is not a mechanism by itself, it can amplify contributions of other mechanisms, especially, in the form of flow diversion. Petroleum reservoirs are highly heterogeneous at all scales. The pore scale is characterized by diversity in the pore geometries and by mixed wettability. On the formation scale, a reservoir is often represented as a layer-cake structure, containing also fractures and other structural elements. The laboratory core samples are never homogeneous, either, as revealed by the X-ray computer tomography (Figure 3).

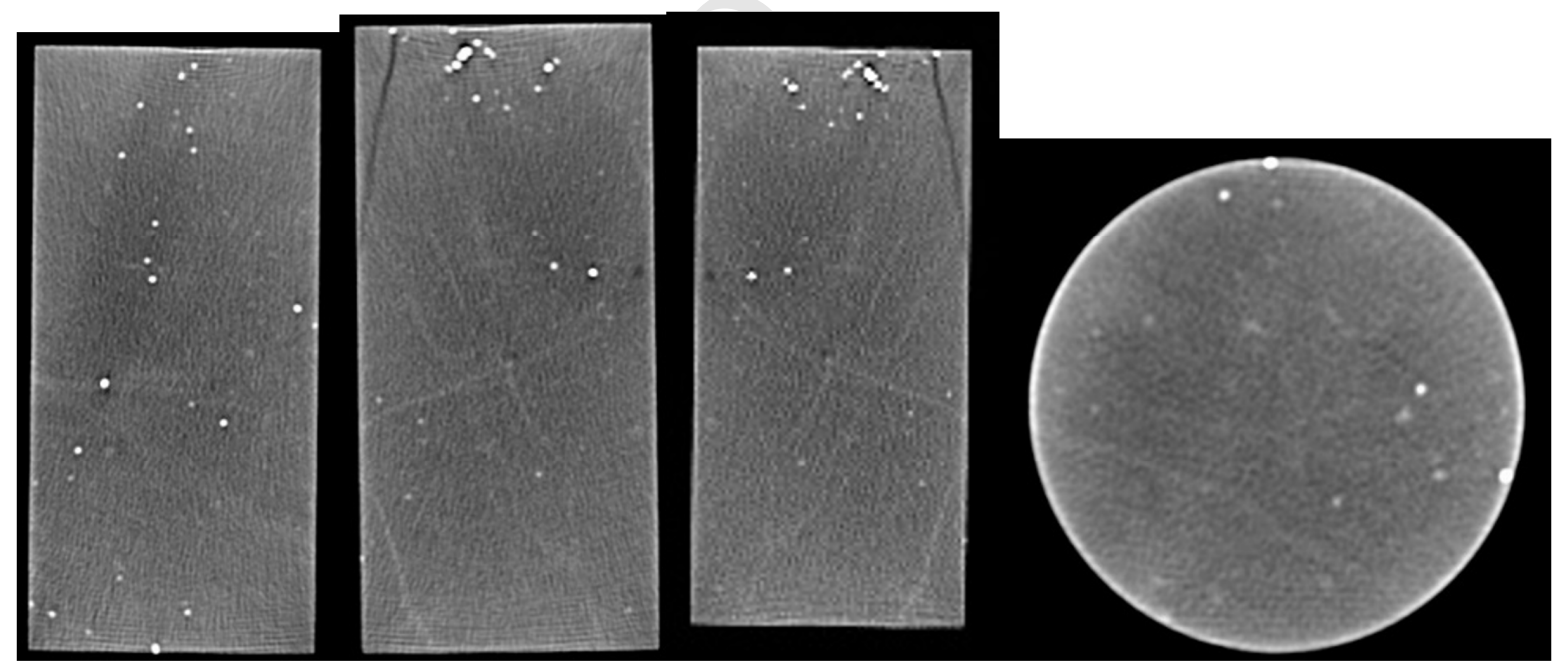

Figure 3. A sample X-ray computer tomography scan of a carbonaceous core sample (limestone from the North Sea).

Impact of heterogeneity on smart waterflooding has not been studied experimentally to a sufficient extent, although it has been recognized and discussed in the literature. Concerning the micro-scale heterogeneity, it was noticed that flooding experiments in a mixed-wet limestone cores are not well repeatable (Loahardjo et al., 2010). The pore geometry and surface structure 
were claimed to be among responsible factors, resulting in the fact that application of enhanced or desalinated brines leads to qualitatively different results for the different rocks (Romanuka et al., 2012).

The core-scale heterogeneity has been regarded as an important factor for the different methods of enhanced oil recovery (Spildo et al., 2012). It may contribute to the recovery via mobilization and relocation of reservoir fines. This effect was extensively studied for the sandstone rocks (AlSarihi et al., 2018; Borazjani et al., 2018; Hussain et al., 2013; Yu et al., 2018). The clay particles contained in the rock may be released, reacting on low salinity of the brine. They travel an insignificant distance and then deposit in narrow capillaries. As a result, permeability in the flooded zones decreases and the injected water is diverted to displace oil from other places. In heterogeneous rocks, this results in more uniform displacement and less bypassed and trapped oil. A set of recovery mechanisms based on re-direction of the injected fluid from the flooded zones has been regarded to as fluid diversion (Spildo et al., 2012). Apart from production of fines, there are other phenomena that may lead to fluid diversion in a carbonaceous rock, such like compaction, precipitation or emulsification. They are addressed elsewhere in the present review.

The work of Zahid et al. (Zahid et al., 2012a, 2012b) compared the recovery under low salinity flooding from a less consolidated Middle East reservoir core, and from a consolidated outcrop core of Aalborg chalk. While the Middle East core reacted on smart waterflooding, the Aalborg chalk core exhibited no additional recovery. This is explained by the rock weakening and fines mobilization in the less consolidated core. It is specially mentioned by Zahid et al. that wettability alteration and surface ion substitution cannot explain observed differences between the two cases. In particular, the surface ion substitution was observed for the Aalborg chalk core, but did not result in additional recovery.

Few simulations reveal the effect of heterogeneity on the macroscale. Attar and Muggeridge (2016) utilized a commercial reservoir simulator in order to study the effect of dispersion on mixing of the injected and formation water under low salinity flooding in a layer-cake reservoir. The coefficient of transversal dispersion (Lake and Hirasaki, 1981) was found to be the main parameter responsible for the effect. Yuan and Shapiro (2011) performed a simulation of the effect of fines precipitation and mobilization in a layer-cake reservoir, applying an approximate method developed by Zhang et al., 2011. Decrease of permeability in the flooded zones had a significant impact and evens propagation of the water-oil displacement front (Yuan and Shapiro, 2011). Zeinijahromi et al. (2011) demonstrated that similar computations may be carried out by application of an option for polymer flooding in a commercial reservoir simulator.

\subsection{Fines}

Formation of the fine particles can occur during smart waterflooding. These particles can appear from mixing of injected and formation water or by releasing the minerals from the rock surface. Production and migration of fines may increase water-wetness of the rock surface. Besides, 
relocation of fines may block some pore throats, diverting the fluid flow and increasing sweep efficiency, as mentioned in the previous subsection. Additionally, appearance of the fines may facilitate formation of the oil-brine-particle emulsions (so-called Pickering emulsions). This mechanism will be considered in the next section.

Fines may appear both in static and dynamic way. While their precipitation due to incompatibility of the injected and formation brines may be regarded as static, mobilization of the inherent reservoir fines requires flow. A positive effect of the fines on recovery is mainly associated with the flow diversion and may only be investigated under flow conditions. That is why we consider the effect of fines as a dynamic phenomenon.

3.3.2. Precipitation from interaction between injected and formation water Madland et al. (2011) pointed out that loss of $\mathrm{Mg}^{2+}$ during injection of a $\mathrm{Mg}^{2+}$ containing brine is not only due to ion substitution, but also due to precipitation of new minerals. SEM images of the core slices confirmed precipitation of the $\mathrm{Mg}$ bearing carbonates and $\mathrm{Mg}$ bearing clay-like minerals. Anhydrate precipitation by injection of a SW-like brine was also confirmed. Puntervold and Austad (2008) suggested that mineral precipitation may also occur due to mixing of seawater and produced water, as a general trend. The more seawater is mixed, the more $\mathrm{CaSO}_{4}$ and $\mathrm{SrSO}_{4}$ precipitates.

Chakravarty et al. (2015a, 2015b, 2015c) analyzed existing imbibition and flooding experimental data. By extensive thermodynamic computations, it was demonstrated that additional production is observed whenever mixing of the formation brine and injected water under experimental thermodynamic conditions results in precipitation of the $\mathrm{CaSO}_{4}$. It was speculated that precipitation occurs in the form of fines. These fines may later be dissolved again when the brine is produced from the core, where temperature and pressure fall down. Inside the core the fines may facilitate formation of the emulsions and diversion of the flow, as discussed in the next section. Precipitation of such fines from an Mg-rich brine was indirectly detected by the NMR spectroscopy (Katika et al., 2015).

\subsubsection{Release of the fines from the rock}

Detachment and relocation of fines has been considered as one of the primary mechanisms for action of low salinity waterflooding in sandstones (Al-Sarihi et al., 2018; Tang and Morrow, 1999). Injection of low salinity brine results in released clay particles (fines) from the sandstone rock. These fines are relocated by the flow of water and further plug narrow pores on their flow path, resulting in a diverted water flow into non-flooded areas. Zeinijahromi et al. (2011, 2013, 2015) showed a significant effect of fines migration, with consequent permeability damage, on sweep efficiency during low salinity waterflooding.

Similar effects have been observed for recovery from the chalk rocks, for example, by application of the fresh water injection to the Middle East chalk (Zahid et al., 2012a). Many 
chalk rocks are not well consolidated and "produce" fines just by touching them. During flooding, fines may promote emulsification, as considered in detail in the next section.

The detachment can be triggered by instability of electric forces induced by variation of ionic strength. DLVO theory was employed to predict stability of fine particles and indicates a decreased stability during low salinity flooding (Schembre et al., 2006). Detachment of fines can also be a result of mineral dissolution. Pu et al. (2010) proposed that dissolution of anhydrate cement in sandstone leads to release of dolomite crystals and other embedded minerals. Similar phenomena may be observed in carbonates.

\subsection{Emulsion formation}

Brine and oil can form emulsions, especially, in the presence of solid particles. Although the literature on emulsions is overwhelming, the studies related to waterflooding in carbonates are not multiple.

Formation of emulsions requires usually a certain mechanism of mixing, like stirring or vibrations. Only in rare cases the emulsions form spontaneously. A porous medium works as a "natural emulsifier", mixing the flowing liquids. That is why formation of emulsions is regarded to as a dynamic phenomenon requiring a flow or another mixing mechanism in order to appear.

Emulsions may play an important role in smart waterflooding. The efficient viscosities of emulsions are high; if the emulsion drop sizes are comparable to the pore sizes, the pores may be plugged, and the injected water may be re-directed to the non-flooded zones. Thus, emulsion formation may contribute to fluid diversion.

\subsubsection{Emulsion formation at the brine-oil contacts}

A study of Emadi and Sohrabi (2013) based on application of the micro-models under reservoir conditions revealed that, when a low salinity brine was in contact with certain crude oil, water micro-dispersions were formed in the oil phase near the oil/water interface. Formation and precipitation of the micro-dispersions could only be observed under high magnifications. Presence of a low salinity injected brine, of the high salinity formation water, and of the mixedwet rock were found to be necessary conditions for emulsification.

Mahzari and Sohrabi (2014) brought different crude oil samples in contact with brines of different salinities. Spontaneous formation of water-in-oil dispersions occurred when salinity of the brine was below 2000 ppm, in agreement with the work of Emadi and Sohrabi (2013).

\subsubsection{Fines assisted emulsification}

Chakravarty et al. (2015a, 2015b, 2015c) suggested that mobile fines formed in a pore space during smart water flooding may lead to emulsion formation, which enhances the mobility of the oil phase and therefore increases the displacement efficiency. A mixture of fines, model oil and deionized water was studied in these experiments. Different water insoluble salts, including 
$\mathrm{Li}_{2} \mathrm{CO}_{3}, \mathrm{CaCO}_{3}, \mathrm{MgCO}_{3}, \mathrm{CaSO}_{4}, \mathrm{SrSO}_{4}$ and $\mathrm{BaSO}_{4}$, formed fines. It was concluded that the fines interact with crude oil in the presence of a low salinity water and produce oil-in-water emulsions. Formation of oil micelles was only possible under presence of polar hydrocarbons in oil. It was also pointed out that light alkanes prefer forming emulsions with light acids, while heavy alkanes require heavier acids. In these studies it was also verified that fines may appear as a result of incompatibility between injected brine and formation water (as described in the previous section). Formation of such fines promotes in situ emulsification.

Arshad et al. (2017) investigated the effect of $\mathrm{CaCO}_{3}$ and $\mathrm{CaSO}_{4}$ fines on emulsification with model (decane and hexane-hexadecane) and North Sea crude oils with deionized water, seawater and formation water. The sonification method was applied to create emulsions. Increase in emulsion formation and better emulsion stability was observed with increasing the amount of fines (Arshad et al., 2017). This study confirmed the results of Chakravarty et al. (2015a, 2015b, 2015c) that the distilled water emulsifies better than the seawater when synthetic oils are involved. However, a North Sea crude oil formed equal or larger amounts of emulsions with seawater than with distilled water. In another experimental study Arshad et al., (2018) focused on understanding the role of particle sizes on emulsification. This study involved particles of the sizes between 15 and $90 \mathrm{~nm}$. For the model oils, larger amounts of emulsions with smaller droplet sizes were formed with smaller particles. Decrease of salinity also facilitated formation of emulsions. However, formation of emulsions with a North Sea oil did not show any significant dependence on the particle sizes and brine salinity.

\subsubsection{Effect of $\mathrm{pH}$ on emulsification}

Formation of emulsions is often attributed to activity of natural surfactants, like organic acids, on the water-oil interface. The value of $\mathrm{pH}$ affects this activity. This value is determined by the composition of an injected brine. Additionally, chemical interactions between rock, initial water and injected brine may cause increase in the $\mathrm{pH}$ by cation exchange or mineral dissolution.

Previous studies showed importance of the $\mathrm{pH}$ for emulsion formation by in-situ surfactants. Buckley et al. (1989) pointed out that dissolution of organic acids, which is dependent on $\mathrm{pH}$, can take place at a water/oil interface. Addition of weak acids and bases to water may lead to well-buffered $\mathrm{pH}$, which is maintained despite of the ionization of polar components of oil at the interface. Hirasaki and Zhang (2004) investigated the effect of alkaline surfactant solutions on carbonate reservoirs during imbibition tests and concluded that moderately high $\mathrm{pH}$ obtained from alkali solutions generated natural surfactants from naphthenic acids contained in the crude oil by in situ saponification. Rezaei Gomari and Hamouda (2006) implied that generation of surfactants from residual oil at elevated $\mathrm{pH}$ was the main low salinity recovery mechanism. Elevated $\mathrm{pH}$ can enhance oil recovery in several ways: generation of surfactant, change in wettability and reduction in IFT (McGuire et al., 2005; Rezaei Gomari and Hamouda, 2006). 
Summarizing, formation of emulsions may be facilitated by production of fines and change of the $\mathrm{pH}$ of the solution. In situ formation of the emulsions may result in plugging waterflooded zones and diversion of the injected brine to displace oil from un-flooded zones.

\section{General Discussion and Conclusion}

We have overviewed the studies directed onto investigation of the possible chemical and physical mechanisms resulting in additional recovery under smart waterflooding of the carbonate rocks. We have attempted also to classify the works according to the investigated mechanisms. This classification is necessarily imperfect, since may studies consider multiple phenomena occurring simultaneously (which validates their mentioning in the different sections). However, on the positive side, we believe that nearly all the phenomena important for smart waterflooding have been described in the literature; and they have been mentioned in this review. It is unlikely that in the nearest future a totally new and unknown mechanism of recovery for smart waterflooding will be revealed.

A common point of agreement between the different authors is that it is possible, indeed, to increase recovery in carbonates by application of smartly composed and selected brines. However, here the agreement ends. The researchers argue for importance of potential determining ions in the brine (in different combinations: calcium, magnesium, sulfates, bicarbonate, other specific ions). Other works demonstrate efficiency of the low salinity water injection. There are also works claiming success of both specific ions and fresh water; or of neither of them.

The smart waterflooding mechanisms may roughly be divided into static (appearing in equilibrium) and dynamic (related to the flow). A more detailed classification is hardly possible. Many mechanisms work in combination, like expansion of the double layer and formation of the bonds (complexation) on the rock surface; or fines precipitation, emulsion formation and fluid diversion. At present, it is difficult to conclude about relative contributions of the specific mechanisms to gain additional recovery. Most probably, the recovery mechanisms work in combination and/or are differently important for specific carbonaceous rocks. The future experimental research should be designed in such a way that makes it possible to study the different mechanisms separately, confirming their importance or excluding them. An observation that phenomenon $\mathrm{A}$ is observed in the recovery process $\mathrm{B}$ is not sufficient to assert that $\mathrm{A}$ is a reason for B. It should, at least, be checked that A results in success of B in all the cases reported in the literature. In other words, not only positive, but also negative observations should be reported, and Propper's criterion of falsifiability should be verified.

Analysis of the importance of the different mechanisms of smart waterflooding is complicated by the fact that many experimental parameters are not reported or measured. Among the least often reported factors, are: exact timing of the experiment, mineral composition of the rock, homogeneity or heterogeneity of the rock samples, degree of their consolidation, compositions of the oil and effluent, production of fines, emulsification (or not), and other. In many cases, a more comprehensive analysis of experimental conditions, than provided by the authors, is required in order to make a definite conclusion about an actually working recovery mechanism. It is 
important to extract quantitative information whenever possible (e.g. analysis of the dependence of the residual saturations on the value of capillary number). Characteristic time scales for the different determining processes (e.g. ion adsorption) are also insufficiently studied. As stated by Bartels et al. (2017), analysis of the different processes with regard to the characteristic time and length scales may be a subject for the future research.

Experimental conclusions must be complemented and verified by a proper modeling. At present, models for most of the recovery mechanisms, both static and dynamic, are well established and match experimental results, at least, qualitatively. However, their predictive capability regarding expected recovery is not high. The main parameters, like residual saturations and characteristic times of the process, cannot be estimated in advance, without direct matching the performed flooding experiments. There is no way to evaluate these parameters better than within an order of magnitude, based on independent experiments. On the other hand, any reasonable flow model incorporating a relevant recovery mechanism and using residual saturations and characteristic relaxation times as adjustment parameters will be capable of matching the core flooding data within their accuracy. The models can well capture the recovery physics and chemistry, provided that it is known; however, it is unlikely that they may help discriminating between the different recovery mechanisms. This problem may probably be partly overcome by development of the advanced models involving multiscale analysis and averaging. However, necessary experimental information will still be missing there.

In sum, direct flooding tests are unavoidable at the present level of knowledge, but they should be supplemented by detailed accompanying experimental studies, like measurements of the oilwater-rock interactions or the experiments involving ordinary and micro CT scanning and other ways of non-invasive flow monitoring. The static mechanisms are probably unable to explain the observed variety of the experimental results, and the recovery mechanisms based on flow dynamics should also be involved. A large body of experimental work has already been carried out and may be served as a basis for further analysis; however, many questions still remain open and require further studies.

\section{References}

Afekare, D.A., Radonjic, M., 2017. From Mineral Surfaces and Coreflood Experiments to Reservoir Implementations: Comprehensive Review of Low-Salinity Water Flooding (LSWF). Energy and Fuels 31, 13043-13062. https://doi.org/10.1021/acs.energyfuels.7b02730

Aghaeifar, Z., Strand, S., Austad, T., Puntervold, T., Aksulu, H., Navratil, K., Storås, S., Håmsø, D., 2015. Influence of Formation Water Salinity/Composition on the Low-Salinity Enhanced Oil Recovery Effect in High-Temperature Sandstone Reservoirs. Energy and Fuels 29, 4747-4754. https://doi.org/10.1021/acs.energyfuels.5b01621

Aharonov, E., Spiegelman, M., 1997. Three-dimensional flow and reaction in porous media: Implication for the Earth's mantle and sedimentary basins. Jouranl Geophys. Res. 102, 821833.

Al-Attar, H.H., Mahmoud, M.Y., Zekri, A.Y., Almehaideb, R., Ghannam, M., 2013. Low- 
salinity flooding in a selected carbonate reservoir: Experimental approach. J. Pet. Explor. Prod. Technol. 3, 139-149. https://doi.org/10.1007/s13202-013-0052-3

Al-Sarihi, A., Zeinijahromi, A., Genolet, L., Behr, A., Kowollik, P., Bedrikovetsky, P., 2018. Effects of Fines Migration on Residual Oil during Low-Salinity Waterflooding. Energy and Fuels 32, 8296-8309. https://doi.org/10.1021/acs.energyfuels.8b01732

Al-Shalabi, E.W., Sepehrnoori, K., Pope, G., 2014. Mysteries behind the Low Salinity Water Injection Technique. J. Pet. Eng. 2014, 1-11. https://doi.org/10.1155/2014/304312

Alagic, E., Spildo, K., Skauge, A., Solbakken, J., 2011. Effect of crude oil ageing on low salinity and low salinity surfactant flooding. J. Pet. Sci. Eng. 78, 220-227. https://doi.org/10.1016/j.petrol.2011.06.021

Alameri, W., Teklu, T.W., Graves, R.M., Kazemi, H., AlSumaiti, A.M., 2014. Wettability Alteration During Low-Salinity Waterflooding in Carbonate Reservoir Cores, in: SPE Asia Pacific Oil \& Gas Conference and Exhibition. Adelaide, Australia. https://doi.org/10.2118/171529-MS

Alexeev, A., 2015. Modeling of Salinity Effects on Waterflooding of Petroleum Reservoirs. Technical University of Denmark.

Alexeev, A., Shapiro, A., Thomsen, K., 2015. Modeling of Dissolution Effects on Waterflooding. Transp. Porous Media 106, 545-562. https://doi.org/10.1007/s11242-0140413-5

Alshakhs, M.J., Kovscek, A.R., 2016. Understanding the role of brine ionic composition on oil recovery by assessment of wettability from colloidal forces. Adv. Colloid Interface Sci. 233, 126-138. https://doi.org/10.1016/j.cis.2015.08.004

Alvarado, V., Bidhendi, M.M., Garcia-olvera, G., Morin, B., Oakey, J.S., 2014. Interfacial Visco-Elasticity of Crude Oil - Brine : An Alternative EOR Mechanism in Smart Waterflooding. SPE Improv. Oil Recover. Symp. 1-17. https://doi.org/10.2118/169127-MS

Andersen, P., Evje, S., Madland, M. V., Hiorth, A., 2012. A geochemical model for interpretation of chalk core flooding experiments. Chem. Eng. Sci. 84, 218-241. https://doi.org/10.1016/j.ces.2012.08.038

Arshad, M.W., Feilberg, K.L., Shapiro, A., Thomsen, K., 2018. Characterization of Emulsion Formation With Nanoparticles for Enhanced Oil Recovery. SPE Kingdom Saudi Arab. Annu. Tech. Symp. Exhib. 23-26 April. Dammam, Saudi Arab. https://doi.org/https://doi.org/10.2118/192170-MS

Arshad, M.W., Loldrup Fosbøl, P., Shapiro, A., Thomsen, K., 2017. Water-Oil Emulsions with Fines in Smart Water Enhanced Oil Recovery. SPE Kuwait Oil Gas Show Conf. https://doi.org/10.2118/187620-MS

Attar, A., Muggeridge, a H., 2016. Evaluation of Mixing in Low Salinity Waterflooding. SPE EOR Conf. Oil Gas West Asia 21-23. https://doi.org/10.2118/179803-MS

Austad, T., 2013. Water-Based EOR in Carbonates and Sandstones: New Chemical Understanding of the EOR Potential Using "Smart Water," First Edit. ed, Enhanced Oil 
Recovery Field Case Studies. Elsevier Inc. https://doi.org/10.1016/B978-0-12-3865458.00013-0

Austad, T., Rezaeidoust, A., Puntervold, T., 2010. Chemical Mechanism of Low Salinity Water Flooding in Sandstone Reservoirs, in: SPE Improved Oil Recovery Symposium. Tulsa, Oklahoma, U.S.A. https://doi.org/10.2118/129767-MS

Austad, T., Shariatpanahi, S.F., Strand, S., Black, C.J.J., Webb, K.J., 2012. Conditions for a lowsalinity Enhanced Oil Recovery (EOR) effect in carbonate oil reservoirs. Energy and Fuels 26, 569-575. https://doi.org/10.1021/ef201435g

Austad, T., Shariatpanahi, S.F., Strand, S., Aksulu, H., Puntervold, T., 2015. Low Salinity EOR Effects in Limestone Reservoir Cores Containing Anhydrite: A Discussion of the Chemical Mechanism. Energy and Fuels 29, 6903-6911. https://doi.org/10.1021/acs.energyfuels.5b01099

Austad, T., Standnes, D.C., 2003. Spontaneous imbibition of water into oil-wet carbonates. J. Pet. Sci. Eng. 39, 363-376. https://doi.org/10.1016/S0920-4105(03)00075-5

Austad, T., Strand, S., Madland, M. V., Puntervold, T., Korsnes, R.I., 2007. Seawater in Chalk: An EOR and Compaction Fluid, in: International Petroleum Technology Conference. Dubai, UAE. https://doi.org/10.2118/118431-PA

Ayirala, S.C., Yousef, A.A., 2016. A critical review of water chemistry alteration technologies to develop novel water treatment schemes for smartwater flooding in carbonate reservoirs, in: SPE Symposium on Improved Oil Recovery Conference. Tulsa, Oklahoma, U.S.A. https://doi.org/https://doi.org/10.2118/179564-MS

Ayirala, S.C., Al-Saleh, S.H., Al-Yousef, A.A., 2017a. Microscopic scale interactions of water ions at crude oil/water interface and their impact on oil mobilization in advanced water flooding. J. Pet. Sci. Eng. 163, 640-649. https://doi.org/10.1016/j.petrol.2017.09.054

Ayirala, S.C., AlYousef, A.A., Li, Z., Xu, Z., 2017b. Water Ion Interactions at Crude Oil-Water Interface: A New Fundamental Understanding on SmartWater Flood, in: SPE Middle East Oil \& Gas Show and Conference. Manama, Kingdom of Bahrain. https://doi.org/10.2118/183894-MS

Bartels, W.B., Mahani, H., Berg, S., Hassanizadeh, S.M., 2019. Literature review of low salinity waterflooding from a length and time scale perspective. Fuel 236, 338-353. https://doi.org/10.1016/j.fuel.2018.09.018

Bedrikovetsky, P., Silva, R.M.P., Daher, J.S., Gomes, J.A.T., Amorim, V.C., 2009. Well-databased prediction of productivity decline due to sulphate scaling. J. Pet. Sci. Eng. 68, 60-70. https://doi.org/10.1016/j.petrol.2009.06.006

Bedrikovetsky, P.G., 1993. Mathematical Theory of Oil and Gas Recovery. Kluwer Pub.

Bedrikovetsky, P.G., Mackay, E.J., Silva, R.M.P., Patricio, F.M.R., Rosário, F.F., 2009. Produced water re-injection with seawater treated by sulphate reduction plant: Injectivity decline, analytical model. J. Pet. Sci. Eng. 68, 19-28.

https://doi.org/10.1016/j.petrol.2009.05.015 
Bernard G.G., 1967. Effect of Floodwater Slinity on Recovery of Oil from Cores Containing Clays. SPE J. https://doi.org/10.2118/1725-MS

Boade, R.R., Chin, L.Y., Siemers, W.T., 1989. Forecasting of Ekofisk Reservoir Compaction and Subsidence by Numerical Simulation. J. Pet. Technol. 41. https://doi.org/10.2118/17855-pa

Borazjani, S., Behr, A., Genolet, L.C., Kowollik, P., 2018. Fines-Migration-Assisted Waterflooding to Improve Sweep Efficiency Analytical Model, in: SPE International Conference and Exhibition on Formation Damage Control. Lafayette, Louisiana, USA.

Buckley, J.S., Takamura, K., Morrow, N.R., 1989. Influence of Electrical Surface Charges on the Wetting Properties of Crude Oils. SPE Reserv. Eng. 332-340.

Chakravarty, K.H., Fosbøl, P.L., Thomsen, K., 2015a. Interactions of fines with base fractions of oil and its implication in smart water flooding. SPE. https://doi.org/10.2118/173855-MS

Chakravarty, K.H., Fosbøl, P.L., Thomsen, K., 2015b. Fine formation during brine-crude oilcalcite interaction in smart water enhanced oil recovery for Caspian carbonates, in: Society of Petroleum Engineers - SPE Annual Caspian Technical Conference and Exhibition. Baku, Azerbaijan.

Chakravarty, K.H., Fosbøl, P.L., Thomsen, K., 2015c. Significance of fines and their correlation to reported oil recovery, in: Society of Petroleum Engineers - Abu Dhabi International Petroleum Exhibition and Conference. Abu Dhabi, UAE.

Chandrasekhar, S., Mohanty, K.K., 2013. Wettability Alteration with Brine Composition in High Temperature Carbonate Reservoirs. SPE J.

Chin, L.Y., Thomas, L.K., 1999. Fully Coupled Analysis of Improved Oil Recovery by Reservoir Compaction, in: SPE Annual Technical Conference and Exhibition. Houston, Texas, USA. https://doi.org/10.2118/56753-ms

Criddle, D.W., Meader, A.L., 1955. Viscosity and elasticity of oil surfaces and oil-water interfaces. J. Appl. Phys. 26, 838-842. https://doi.org/10.1063/1.1722104

Dandekar, A.Y., 2013. Petroleum reservoir rock and fluid properties, 2nd ed. CRC Press. https://doi.org/10.1006/jesp.1998.1365

Derjaguin, B., Landau, L., 1941. Theory of the stability of strongly charged lyophobic sols and of the adhesion of strongly charged particles in solutions of electrolytes. Prog. Surf. Sci. 43, 30-59. https://doi.org/10.1016/0079-6816(93)90013-L

Derkani, M.H., Fletcher, A., Abdallah, W., Sauerer, B., Anderson, J., Zhang, Z., 2018. Low Salinity Waterflooding in Carbonate Reservoirs: Review of Interfacial Mechanisms. Colloids and Interfaces 2, 20. https://doi.org/10.3390/colloids2020020

Eftekhari, A.A., Thomsen, K., Stenby, E.H., Nick, H.M., 2017. Thermodynamic Analysis of Chalk-Brine-Oil Interactions. Energy and Fuels 31, 11773-11782. https://doi.org/10.1021/acs.energyfuels.7b02019

Elimelech, M., Gregory, J., Jia, X., Williams, R.., 1998. Particle Deposition and Aggregation 
Measurement, Modelling and Simulaiton (Colloid \& Surface Engineering). ButterworthHeinemann, Oxford, UK.

Emadi, A., Sohrabi, M., 2013. Visual Investigation of Oil Recovery by LowSalinity Water Injection: Formation of Water Micro-Dispersions and WettabilityAlteration, in: SPE Annual Technical Conference and Exhibition. New Orleans, Louisiana, USA. https://doi.org/10.2118/166435-MS

Erzuah, S., Fjelde, I., Omekeh, A.V., 2017. Wettability Estimation by Surface Complexation Simulations, in: SPE Europec Featured at 79th EAGE Conference and Exhibition. Paris, France. https://doi.org/10.2118/185767-MS

Evje, S., Hiorth, A., Madland, M. V, Korsnes, R.I., 2009. A Mathematical Model Relevant for Weakening of Chalk Reservoirs Due to Chemical Reactions. Networks Heterog. Media 4, 755-788. https://doi.org/10.3934/nhm.2009.4.755

Fathi, S.J., Austad, T., Strand, S., 2011. Water-based enhanced oil recovery (EOR) by "smart water": Optimal ionic composition for EOR in carbonates. Energy and Fuels 25, 51735179. https://doi.org/10.1021/ef201019k

Fathi, S.J., Austad, T., Strand, S., 2010. "smart water" as a wettability modifier in chalk: The effect of salinity and ionic composition. Energy and Fuels 24, 2514-2519. https://doi.org/10.1021/ef901304m

Gachuz-muro, H., Sohrabi, M., 2017. Prediction, Control and Validation of Rock Dissolution During Smart Water Injection and Its Impact on Waterflood Performance in Heavy Oil Carbonate Reservoirs, in: International Symposium of the Society of Core Analyst. Vienna, Austria. https://doi.org/CMI1415 [pii]|r10.1111/j.1462-5822.2009.01415.x

Gachuz-muro, H., Watt, H., Sohrabi, M., 2016. Natural Generation of Acidic Water as a Cause of Dissolution of the Rock During Smart Water Injection in Heavy Oil Carbonate Reservoirs, in: SPE Latin America and Caribbean Heavy Oil Conference. Lima, Peru.

Gachuz-muro, H., Watt, H., Sohrabi, M., 2013. Effects of brine on Crude Oil viscosity at different temperature and brine composition - heavy oil/water interaction, in: EAGE Annual Conference \& Exhibition Incorporating. Society of Petroleum Engineers. London, UK. https://doi.org/10.2118/164910-MS

Gandomkar, A., Rahimpour, M.R., 2015. Investigation of Low-Salinity Waterflooding in Secondary and Tertiary Enhanced Oil Recovery in Limestone Reservoirs. Energy and Fuels 29, 7781-7792. https://doi.org/10.1021/acs.energyfuels.5b01236

Goolsby, J.L., Anderson, R.C., 1964. Pilot Water Flooding in a Dolomite Reservoir, The McElroy Field, in: SPE Secondary Recovery Symposium. Wichita Falls, Texas, USA.

Graue, A., Fermi, M.A., Moe, R.W., Baldwin, B.A., Needham, R., 2012. Water Mixing During Waterflood Oil Recovery: The Effect of Initial Water Saturation. SPE J. 17, 43-52. https://doi.org/10.2118/149577-PA

Gupta, R., Smith Jr., P.G., Hu, L., Willingham, T.W., Lo Cascio, M., Shyeh, J.J., Harris, C.R., 2011. Enhanced waterflood for Middle East carbonate cores - Impact of injection water composition, in: SPE Middle East Oil and Gas Show and Conference. Manama, Bahrain. 
https://doi.org/10.2118/142668-MS

Hallenbeck, L.D., Sylte, J.E., Ebbs, D.J., Thomas, L.K., 1991. Implementation of the Ekofisk Field Waterflood. SPE Form. Eval. 6, 284-290.

https://doi.org/10.7860/JCDR/2017/24192.9615

Hamouda, A.A., Maevskiy, E., 2014. Oil recovery mechanism(s) by low salinity brines and their interaction with chalk. Energy and Fuels 28, 6860-6868. https://doi.org/10.1021/ef501688u

Hamouda, A.A., Rezaei Gomari, K.A., 2006. Influence of Temperature on Wettability Alteration of Carbonate Reservoirs, in: SPE/DOE Symposium on Improved Oil Recovery. Tulsa, Oklahoma, U.S.A. https://doi.org/10.1016/j.saa.2014.06.016

Hasiba, H.H., Jessen. F.W, 1966. Film properties of interfance-active compounds adsorbed from crude oils at the oil/water interface. SPE J.

Heggheim, T., Madland, M. V., Risnes, R., Austad, T., 2004. A chemical induced enhanced weakening of chalk by seawater. J. Pet. Sci. Eng. 46, 171-184.

https://doi.org/10.1016/j.petrol.2004.12.001

Hellmann, R., Renders, P.J.N., Gratier, J.-P., Guiguet, R., 2002. Experimental Pressure Solution Compaction of Chalk in Aqueous Solutions: Part 1. Deformation Behavior and Chemistry, in: Hellmann, R.S.A.W. (Ed.), Water-Rock Interactions, Ore Deposits, and Environmental Geochemistry: A Tribute to David A. Crerar. The Geochemical Society, pp. 129-152.

Hiorth, A., Cathles, L.M., Madland, M. V., 2010. The Impact of Pore Water Chemistry on Carbonate Surface Charge and Oil Wettability. Transp. Porous Media 85, 1-21. https://doi.org/10.1007/s11242-010-9543-6

Hirasaki, G., Zhang, D.L., 2004. Surface Chemistry of Oil Recovery From Fractured, Oil-Wet, Carbonate Formations. SPE J. 9, 151-162. https://doi.org/10.2118/88365-PA

Hirasaki, G.J., 1991. Wettability: Fundamentals and Surface Forces. SPE Form. Eval. 6, 217226. https://doi.org/10.2118/17367-PA

Houston, S.J., Yardley, B.W.D., Leeds, U., Smalley, P.C., Collins, I., 2006. Precipitation and Dissolution of Minerals During Waterflooding of a North Sea Oil Field, in: SPE International Oilfield Scale Symposium. Aberdeen, Scotland, UK.

Hussain, F., Zeinijahromi, A., Bedrikovetsky, P., Badalyan, A., Carageorgos, T., Cinar, Y., 2013. An experimental study of improved oil recovery through fines-assisted waterflooding. J. Pet. Sci. Eng. 109, 187-197. https://doi.org/10.1016/j.petrol.2013.08.031

Høeg, K., Gutierrez, M., Øino, L.E., 2000. The Effect of Fluid Content on the Mechanical Behaviour of Fractures in Chalk. Rock Mech. Rock Eng. 33, 93-117. https://doi.org/10.1007/s006030050037

Høiland, L.K., Spildo, K., Skauge, A., 2007. Fluid flow properties for different classes of intermediate wettability as studied by network modelling. Transp. Porous Media 70, 127146. https://doi.org/10.1007/s11242-006-9088-x

Jackson, M.D., Vinogradov, J., Hamon, G., Chamerois, M., 2016. Evidence, mechanisms and 
improved understanding of controlled salinity waterflooding part 1: Sandstones. Fuel 185, 772-793. https://doi.org/10.1016/j.fuel.2016.07.075

Johnson, J.P., Rhett, D.W., Johnsen, Rhett, D.W., Johnson, J.P., Rhett, D.W., 1986. Compaction Behavior of Ekofisk Chalk as a Function of Stress, in: SPE European Petroleum Conference. London, UK. https://doi.org/10.2118/15872-MS

Karimi, M., Al-Maamari, R.S., Ayatollahi, S., Mehranbod, N., 2016. Wettability alteration and oil recovery by spontaneous imbibition of low salinity brine into carbonates: Impact of Mg2+, SO42-and cationic surfactant. J. Pet. Sci. Eng. 147, 560-569. https://doi.org/10.1016/j.petrol.2016.09.015

Karoussi, O., Hamouda, A.A., 2007. Imbibition of sulfate and magnesium ions into carbonate rocks at elevated temperatures and their influence on wettability alteration and oil recovery. Energy and Fuels 21, 2138-2146. https://doi.org/10.1021/ef0605246

Katika, K., Addassi, M., Alam, M.M., Fabricius, I.L., 2015. The effect of divalent ions on the elasticity and pore collapse of chalk evaluated from compressional wave velocity and lowfield Nuclear Magnetic Resonance (NMR). J. Pet. Sci. Eng. 136, 88-99. https://doi.org/10.1016/j.petrol.2015.10.036

Katika, K., Alam, M.M., Alexeev, A., Chakravarty, K.H., Fosbøl, P.L., Revil, A., Stenby, E., Xiarchos, I., Yousefi, A., Fabricius, I.L., 2018. Elasticity and electrical resistivity of chalk and greensand during water flooding with selective ions. J. Pet. Sci. Eng. 161, 204-218. https://doi.org/10.1016/j.petrol.2017.11.045

Khaksar Manshad, A., Olad, M., Taghipour, S.A., Nowrouzi, I., Mohammadi, A.H., 2016. Effects of water soluble ions on interfacial tension (IFT) between oil and brine in smart and carbonated smart water injection process in oil reservoirs. J. Mol. Liq. 223, 987-993. https://doi.org/10.1016/j.molliq.2016.08.089

Korsnes, R.I., Madland, M. V., Austad, T., Haver, S., Røsland, G., 2008. The effects of temperature on the water weakening of chalk by seawater. J. Pet. Sci. Eng. 60, 183-193. https://doi.org/10.1016/j.petrol.2007.06.001

Kuznetsov, D., Cotterill, S., Oil, T., Marie, ;, Giddins, A., Blunt, M.J., 2015. SPE-174615-MS Low-Salinity Waterflood Simulation: Mechanistic and Phenomenological Models, in: SPE Enhanced Oil Recovery Conference. Kuala Lumpur, Malaysia. https://doi.org/10.2118/174615-MS

Lager, A., Webb, K.J., Black, C.J.J., Singleton, M., Sorbie, K.S., 2008a. Low Salinity Oil Recovery - An Experimental Investigation. Petrophysics 49, 28-35.

Lager, A., Webb, K.J., Collins, I.R., Richmond, D.M., 2008b. LoSal Enhanced Oil Recovery: Evidence of Enhanced Oil Recovery at the Reservoir Scale, in: SPE Symposium on Improved Oil Recovery Symposium. Tulsa, Oklahoma, U.S.A. https://doi.org/10.2118/113976-MS

Lake, L.W., Hirasaki, G.J., 1981. Taylor $\hat{a}^{\mathrm{TM}}$ s Dispersion in Stratified Porous Media. SPE J. 459-468.

Lam, E.J., Alvarez, M.N., Galvez, M.E., Alvarez, E.B., 2008. A model for calculating the 
density of aqueous multicomponent electrolyte solutions. J. Chil. Chem. Soc. 53, 14041409. https://doi.org/10.4067/S0717-97072008000100015

Lashkarbolooki, M., Ayatollahi, S., Riazi, M., 2017. Mechanistical study of effect of ions in smart water injection into carbonate oil reservoir. Process Saf. Environ. Prot. 105, 361-372. https://doi.org/10.1016/j.psep.2016.11.022

Loahardjo, N., Xie, X., Morrow, N.R., 2010. Oil recovery by sequential waterflooding of mixedwet sandstone and limestone. Energy and Fuels 24, 5073-5080. https://doi.org/10.1021/ef100729b

Madland, M.V., Korsnes, R.I., Risnes, R., 2002. Temperature effects in Brazilian , uniaxial and triaxial compressive tests with high porosity chalk, in: SPE Annual Technical Conference and Exhibition. San Antonio, TX, USA. https://doi.org/10.2118/77761-MS

Madland, M. V., Finsnes, A., Alkafadgi, A., Risnes, R., Austad, T., 2006. The influence of CO2gas and carbonate water on the mechanical stability of chalk. J. Pet. Sci. Eng. 51, 149168. https://doi.org/10.1016/j.petrol.2006.01.002

Madland, M. V., Hiorth, A., Omdal, E., Megawati, M., Hildebrand-Habel, T., Korsnes, R.I., Evje, S., Cathles, L.M., 2011. Chemical Alterations Induced by Rock-Fluid Interactions When Injecting Brines in High Porosity Chalks. Transp. Porous Media 87, 679-702. https://doi.org/10.1007/s11242-010-9708-3

Mahani, H., Keya, A.L., Berg, S., Bartels, W.B., Nasralla, R., Rossen, W.R., 2015. Insights into the mechanism of wettability alteration by low-salinity flooding (LSF) in carbonates. Energy and Fuels 29, 1352-1367. https://doi.org/10.1021/ef5023847

Mahzari, P., Sohrabi, M., 2014. Crude Oil/Brine Interactions and Spontaneous Formation of Micro-Dispersions in Low Salinity Water Injection. SPE Improv. Oil Recover. Symp. https://doi.org/10.2118/169081-MS

McGuire, P.L., Chatham, J.R., Paskvan, F.K., Sommer, D.M., Carini, F.H., 2005. Low Salinity Oil Recovery: An Exciting New EOR Opportunity for Alaska\&amp;apos;s North Slope, in: SPE Western Regional Meeting. Irvine, CA, U.S.A. https://doi.org/10.2118/93903-MS

Mohammadkhani, S., Shahverdi, H., Esfahany, M.N., 2018. Impact of salinity and connate water on low salinity water injection in secondary and tertiary stages for enhanced oil recovery in carbonate oil reservoirs. J. Geophys. Eng. 15, 1242-1254. https://doi.org/10.1088/17422140/aaae84

Mohanty, K.K., Chandrasekhar, S., 2013. Wettability Alteration with Brine Composition in High Temperature Carbonate Reservoirs. SPE Annu. Tech. Conf. Exhib. https://doi.org/10.2118/166280-MS

Mohsenzadeh, A., Pourafshary, P., Al-Wahaibi, Y., 2016. Oil Recovery Enhancement in Carbonate Reservoirs Via Low Saline Water Flooding in Presence of Low Concentration Active Ions; A Case Study, in: SPE EOR Conference at Oil and Gas West Asia. Muscat, Oman. https://doi.org/10.2118/179767-MS

Morrow, N., Buckley, J., 2011. Improved Oil Recovery by Low-Salinity Waterflooding. J. Pet. Technol. 63, 106-112. https://doi.org/10.2118/129421-JPT 
Nermoen, A., Korsnes, R.I., Storm, E.V., Stødle, T., Madland, M.V., Fabricius, I.L., 2018. Incorporating electrostatic effects into the effective stress relation - Insights from chalk experiments. Geophysics 83. https://doi.org/10.1190/geo2016-0607.1

Patil, S., Dandekar, A.Y., Patil, S.L., Khataniar, S., 2008. IPTC 12004 Low Salinity Brine Injection for EOR on Alaska North Slope (ANS), in: International Petroleum Technology Conference. Kuala Lumpur. https://doi.org/10.2523/12004-MS

Pope, G.A., 1980. The Application of Fractional Flow Theory to Enhanced Oil Recovery. Soc. Pet. Eng. J. 20, 191-205. https://doi.org/10.2118/7660-PA

Powell, B.N., Lovell, G.L., 1994. Mechanisms of chalk compaction, in: SPE/ISRM Rock Mechanics in Petroleum Engineering Conference. Delft, The Netherlands. https://doi.org/10.2118/28132-MS

Prieve, D.C., Roman, R., 1987. Diffusiophoresis of a rigid sphere through a viscous electrolyte solution. J. Chem. Soc. Faraday Trans. 2 Mol. Chem. Phys. 83, 1287-1306. https://doi.org/10.1039/F29878301287

Pu, H., Xie, X., Yin, P., Morrow, N.R., 2010. Low Salinity Waterflooding and Mineral Dissolution, in: SPE Annual Technical Conference and Exhibition. Florence, Italy. https://doi.org/10.2118/134042-MS

Puntervold, T., Strand, S., Ellouz, R., Austad, T., 2015. Modified seawater as a smart EOR fluid in chalk. J. Pet. Sci. Eng. 133, 440-443. https://doi.org/10.1016/j.petrol.2015.06.034

Puntervold, T., Strand, S., Austad, T., 2007. New method to prepare outcrop chalk cores for wettability and oil recovery studies at low initial water saturation. Energy and Fuels 21, 3425-3430. https://doi.org/10.1021/ef700323c

Puntervold, T., Austad, T., 2008. Injection of seawater and mixtures with produced water into North Sea chalk formation: Impact of fluid-rock interactions on wettability and scale formation. J. Pet. Sci. Eng. 63, 23-33. https://doi.org/10.1016/j.petrol.2008.07.010

Qiao, C., Johns, R., Li, L., Xu, J., 2015. Modeling Low Salinity Waterflooding in Mineralogically Different Carbonates, in: SPE Annual Technical Conference and Exhibition. Houston, Texas, USA. https://doi.org/10.2118/175018-MS

Rashid, S., Mousapour, M.S., Ayatollahi, S., Vossoughi, M., Beigy, A.H., 2015. Wettability alteration in carbonates during "Smart Waterflood": Underling mechanisms and the effect of individual ions. Colloids Surfaces A Physicochem. Eng. Asp. 487, 142-153. https://doi.org/10.1016/j.colsurfa.2015.09.067

Rassenfoss, S., 2016. Scaling Up Smart Water. J. Pet. Technol. 68, 39-41. https://doi.org/10.2118/0916-0039-JPT

Rezaei Gomari, K.A., Hamouda, A.A., 2006. Effect of fatty acids, water composition and pH on the wettability alteration of calcite surface. J. Pet. Sci. Eng. 50, 140-150. https://doi.org/10.1016/j.petrol.2005.10.007

RezaeiDoust, A., Puntervold, T., Austad, T., 2011. Chemical verification of the EOR mechanism by using low saline/smart water in sandstone. Energy and Fuels 25, 2151-2162. 
https://doi.org/10.1021/ef200215y

Risnes, R., Madland, M. V., Hole, M., Kwabiah, N.K., 2005. Water weakening of chalk Mechanical effects of water-glycol mixtures. J. Pet. Sci. Eng. 48, 21-36. https://doi.org/10.1016/j.petrol.2005.04.004

Romanuka, J., Hofman, J., Ligthelm, D.J., Suijkerbuijk, B., Marcelis, F., Oedai, S., Brussee, N., van der Linde, H., Aksulu, H., Austad, T., 2012. Low Salinity EOR in Carbonates, in: SPE Improved Oil Recovery Symposium. Tulsa, Oklahoma, U.S.A. https://doi.org/10.2118/153869-MS

Rotondi, M., Callegaro, C., Masserano, F., Bartosek, M., 2014. Low Salinity Water Injection: eni' s experience, in: Abu Dhabi International Petroleum Exhibition and Conference. Abu Dhabi, UAE. https://doi.org/http://dx.doi.org/10.2118/171794-MS

Rubin, J., 1983. Transport of reacting solutes in porous media: Relation between mathematical nature of problem formulation and chemical nature of reactions. Water Resour. Res. 19, 1231-1252. https://doi.org/10.1029/WR019i005p01231

Ruddy, I., Andersen, M.A., Pattillo, P.D., Bishlawi, M., Foged, N., 1989. Rock Compressibility, Compaction, and Subsidence in a High-Porosity Chalk Reservoir: A Case Study of Valhall Field. J. Pet. Technol. 41, 741-746. https://doi.org/10.2118/18278-PA

Schembre, J.M., Tang, G.Q., Kovscek, A.R., 2006. Wettability alteration and oil recovery by water imbibition at elevated temperatures. J. Pet. Sci. Eng. 52, 131-148. https://doi.org/10.1016/j.petrol.2006.03.017

Shaddel, S., Tabatabae-Nejad, S.A., 2015. Alkali/Surfactant Improved Low-Salinity Waterflooding. Transp. Porous Media 106, 621-642. https://doi.org/10.1007/s11242-0140417-1

Shaker Shiran, B., Skauge, A., 2013. Enhanced oil recovery (EOR) by combined low salinity water/polymer flooding. Energy and Fuels 27, 1223-1235. https://doi.org/10.1021/ef301538e

Shehata, A.M., Nasr El-Din, H.A., 2015. Spontaneous Imbibition Study: Effect of Connate Water Composition on Low-Salinity Waterflooding in Sandstone Reservoirs, in: SPE Western Regional Meeting. Garden Grove, California, USA. https://doi.org/10.2118/174063-MS

Shehata, A.M., Alotaibi, M.B., Nasr-El-Din, H.A., 2014. Waterflooding in Carbonate Reservoirs: Does the Salinity Matter? SPE Reserv. Eval. Eng. 17, 304-313. https://doi.org/10.2118/170254-PA

Sheng, J., Morel, D., Gauer, P., 2010. Evaluation of the Effect of Wettability Alteration on Oil Recovery in Carbonate Reservoirs Questions, in: AAPG GEO 2010 Middle East Geoscience \& Exhibition. Manama, Bahrain.

Sheng, J.J., 2014. Critical review of low-salinity waterflooding. J. Pet. Sci. Eng. 120, 216-224. https://doi.org/10.1016/j.petrol.2014.05.026

Sheu, E.Y., Shields, M.B., Texaco, R., 1995. Asphaltene Surface Activity at Oil / Water 
Interfaces, in: SPE International Symposium on Oilfield Chemistry. San Antonio, TX, USA.

Skauge, A., Ottesen, B., 2002. A Summary of Experimentally Derived Relative Permeability and Residual Saturation on North Sea Reservoir Cores, in: International Symposium of the Society of Core Analyst. Monterey, California, USA, pp. 1-12.

Sohal, M.A., Thyne, G., Søgaard, E.G., 2016. Review of Recovery Mechanisms of Ionically Modified Waterflood in Carbonate Reservoirs. Energy and Fuels 30, 1904-1914. https://doi.org/10.1021/acs.energyfuels.5b02749

Somasundaran, P., Agar, G.., 1967. The zero point of charge of calcite. J. Colloid Interface Sci. 24, 433-440. https://doi.org/10.1016/0021-9797(67)90241-X

Song, J., Zeng, Y., Wang, L., Duan, X., Puerto, M., Chapman, W.G., Biswal, S.L., Hirasaki, G.J., 2017. Surface complexation modeling of calcite zeta potential measurements in brines with mixed potential determining ions $(\mathrm{Ca} 2+, \mathrm{CO} 32-, \mathrm{Mg} 2+, \mathrm{SO} 42-)$ for characterizing carbonate wettability. J. Colloid Interface Sci. 506, 169-179.

https://doi.org/10.1016/j.jcis.2017.06.096

Spildo, K., Johannessen, A., Skauge, A., 2012. Low Salinity Waterflood at Reduced Capillarity, in: Eighteenth SPE Improved Oil Recovery Symposium. Tulsa, Oklahoma, U.S.A., pp. 113. https://doi.org/10.2118/154236-MS

Spivey, J.P., McCain, W.D., North, R., 2004. Estimating density, formation volume factor, compressibility, methane solubility, and viscosity for oilfield brines at temperatures from 0 to $275^{\circ} \mathrm{C}$, pressures to $200 \mathrm{MPa}$, and salinities to $5.7 \mathrm{~mole} / \mathrm{kg}$. J. Can. Pet. Technol. 43, $52-$ 61. https://doi.org/10.2118/04-07-05

Standnes, D.C., Austad, T., 2000a. Wettability alteration in chalk 2. Mechanism for wettability alteration from oil-wet to water-wet using surfactants. J. Pet. Sci. Eng. 28, 123-143. https://doi.org/10.1016/S0920-4105(00)00084-X

Standnes, D.C., Austad, T., 2000b. Wettability alteration in chalk 1. Preparation of core material and oil properties. J. Pet. Sci. Eng. 28, 111-121. https://doi.org/10.1016/S09204105(00)00083-8

Strand, S., Henningsen, S.C., Puntervold, T., Austad, T., 2017. Favorable Temperature Gradient for Maximum Low-Salinity Enhanced Oil Recovery Effects in Carbonates. Energy and Fuels 31, 4687-4693. https://doi.org/10.1021/acs.energyfuels.6b03019

Strand, S., Høgnesen, E.J., Austad, T., 2006. Wettability alteration of carbonates - Effects of potential determining ions (Ca2+and SO42-) and temperature. Colloids Surfaces A Physicochem. Eng. Asp. 275, 1-10. https://doi.org/10.1016/j.colsurfa.2005.10.061

Strand, S., Standnes, D.C., Austad, T., 2006. New wettability test for chalk based on chromatographic separation of SCN- and SO42-. J. Pet. Sci. Eng. 52, 187-197. https://doi.org/10.1016/j.petrol.2006.03.021

Strand, S., Austad, T., Puntervold, T., Høgnesen, E.J., Olsen, M., Barstad, S.M.F., 2008. "Smart Water" for oil recovery from fractured limestone: A preliminary study. Energy and Fuels 22, 3126-3133. https://doi.org/10.1021/ef800062n 
Sulak, R.M., Thomas, L.K., Boade, R.R., 1991. 3D Reservoir Simulation of Ekofisk Compaction Drive (includes associated papers 24317 and 24400 ). J. Pet. Technol. 43, 1272-1278. https://doi.org/10.2118/19802-PA

Suman, Y.K., Shirif, E., Ibrahim, H., Ala-Ktiwi, A., 2014. Evaluation of Low Saline "Smart Water" Enhanced Oil Recovery in Light Oil Reservoirs. World J. Eng. Technol. 2, 13-22. https://doi.org/10.4236/wjet.2014.21002

Sun, L., Spildo, K., Djurhuus, K., Skauge, A., 2014. Salinity Selection for a Low Salinity WaterLow Salinity Surfactant Process. J. Dispers. Sci. Technol. 35, 551-555. https://doi.org/10.1080/01932691.2013.800456

Sylte, J.E., Thomas, L.K., Rhett, D.W., Bruning, D.D., Nagel, N.B., 1999. Water Induced Compaction in the Ekofisk Field, in: SPE Annual Technical Conference and Exhibition. Houston, Texas, USA. https://doi.org/10.2118/56426-MS

Tang, G.-Q., Morrow, N.R., 1999. Influence of brine composition and fines migration on crude oi/brine/rock interactions and oil recovery. J. Pet. Sci. Eng. 24, 99-111. https://doi.org/10.1016/S0920-4105(99)00034-0

Varadaraj, R., Brons, C., 2012. Molecular origins of crude oil interfacial activity. part 4: Oilwater interface elasticity and crude oil asphaltene films. Energy and Fuels 26, 7164-7169. https://doi.org/10.1021/ef300830f

Verwey.E.J.W, Overbeek.J.T.G, 1948. Theory of the Stability of Luophobic Colloids. Elsevier Amsterdam.

Yousef, A.A., Liu, J.S., Blanchard, G., Al-Saleh, S., Al-Zahrani, T., Al-Zahrani, R., Al-Tammar, H., Al-Mulhim, N., 2012a. Smart Waterflooding: Industry's First Field Test in Carbonate Reservoirs, in: SPE Annual Technical Conference and Exhibition. San Antonio, Texas, USA. https://doi.org/10.2118/159526-MS

Yousef, A.A., Al-Saleh, S., Al-Jawfi, M.S., 2012b. Improved/Enhanced Oil Recovery from Carbonate Reservoirs by Tuning Injection Water Salinity and Ionic Content, in: SPE Improved Oil Recovery Symposium. Tulsa, Oklahoma, U.S.A. https://doi.org/10.2118/154076-MS

Yousef, A.A., Al-Saleh, S., Al-Kaabi, A., Al-Jawfi, M., 2011. Laboratory investigation of the impact of injection-water salinity and ionic content on oil recovery from carbonate reservoirs. SPE Reserv. Eval. Eng. 14, 578-593. https://doi.org/10.2118/137634-PA

Yousef, A.A., Al-Saleh, S., Al-Kaabi, A., Al-Jawfi, M., 2010. Laboratory Investigation of Novel Oil Recovery Method for Carbonate Reservoirs, in: Canadian Unconventional Resources \& International Petroleum Conference. Calgary, Canada.

Yu, M., Hussain, F., Arns, J.Y., Bedrikovetsky, P., Genolet, L., Behr, A., Kowollik, P., Arns, C.H., 2018. Imaging analysis of fines migration during water flow with salinity alteration. Adv. Water Resour. 121, 150-161. https://doi.org/10.1016/j.advwatres.2018.08.006

Yuan, H., Shapiro, A.A., 2011. Induced migration of fines during waterflooding in communicating layer-cake reservoirs. J. Pet. Sci. Eng. 78, 618-626. https://doi.org/10.1016/j.petrol.2011.08.003 
Yutkin, M.P., Mishra, H., Patzek, T.W., Lee, J., Radke, C.J., 2016. Bulk and Surface Aqueous Speciation of Calcite: Implications for Low-Salinity Waterflooding of Carbonate Reservoirs, in: SPE Kingdom of Saudi Arabia Annual Technical Symposium and Exhibition. Dammam, Saudi Arabia. https://doi.org/10.2118/182829-PA

Zaeri, M.R., Hashemi, R., Shahverdi, H., Sadeghi, M., 2018a. Enhanced oil recovery from carbonate reservoirs by spontaneous imbibition of low salinity water. Pet. Sci. 15, 564-576. https://doi.org/10.1007/s12182-018-0234-1

Zaeri, M.R., Shahverdi, H., Hashemi, R., Mohammadi, M., 2018b. Impact of water saturation and cation concentrations on wettability alteration and oil recovery of carbonate rocks using low-salinity water. J. Pet. Explor. Prod. Technol. 1-12. https://doi.org/10.1007/s13202-018$0552-2$

Zahid, A., 2012. Smart Waterflooding in Carbonate Reservoirs. Technical University of Denmark. https://doi.org/10.2118/154508-MS

Zahid, A., Shapiro, A.A., Skauge, A., 2012a. Experimental Studies of Low Salinity Water Flooding Carbonate: A New Promising Approach. SPE EOR Conf. Oil Gas West Asia. https://doi.org/10.2118/155625-MS

Zahid, A., Shapiro, A., Stenby, E.H., Yan, W., 2012b. Managing injected water composition to improve oil recovery: A case study of north sea chalk reservoirs. Energy and Fuels 26, 3407-3415. https://doi.org/10.1021/ef2008979

Zahid, A., Stenby, E.H., Shapiro, A.A., 2010. Improved Oil Recovery in Chalk: Wettability Alteration or Something Else?, in: SPE EUROPEC/EAGE Annual Conference. Barcelona, Spain. https://doi.org/10.2118/131300-MS

Zeinijahromi, A., Machado, F.A., Bedrikovetsky, P.G., 2011. Modified Mathematical Model for Fines Migration in Oil Fields, in: Brasil Offshore Conference and Exhibition. Macea, Brazil, pp. 14-17. https://doi.org/10.2118/143742-MS

Zeinijahromi, A., Nguyen, T.K.P., Bedrikovetsky, P., 2013. Mathematical model for fines migration assisted waterflooding with induced formation damage, Journal of Society of Petroleum Engineers SPEJ, 18(3) June, 518-533.

Zeinijahromi, A., Ahmetgareev, V., Badalyan, A., Khisamov, R., Bedrikovetsky, P., 2015. Case Study of Low Salinity Water Injection in Zichebashskoe Field. J. Pet. Sci. Res. 4, 16-31. https://doi.org/10.12783/jpsr.2015.0401.03

Zhang, P., Tweheyo, M.T., Austad, T., 2007. Wettability alteration and improved oil recovery by spontaneous imbibition of seawater into chalk: Impact of the potential determining ions Ca2+, Mg2+, and SO42-. Colloids Surfaces A Physicochem. Eng. Asp. 301, 199-208. https://doi.org/10.1016/j.colsurfa.2006.12.058

Zhang, P., Tweheyo, M.T., Austad, T., 2006. Wettability alteration and improved oil recovery in chalk: The effect of calcium in the presence of sulfate. Energy and Fuels 20, 2056-2062. https://doi.org/10.1021/ef0600816

Zhang, P., Austad, T., 2006. Wettability and oil recovery from carbonates: Effects of temperature and potential determining ions. Colloids Surfaces A Physicochem. Eng. Asp. 279, 179-187. 
https://doi.org/10.1016/j.colsurfa.2006.01.009

Zhang, P., Austad, T., 2005. The Relative Effects of Acid Number and Temperature on Chalk Wettability. SPE Int. Symp. Oilf. Chem. 3-9. https://doi.org/10.2118/92999-MS

Zhang, X., Shapiro, A., Stenby, E.H., 2011. Gravity Effect on Two-Phase Immiscible Flows in Communicating Layered Reservoirs. Transp. Porous Media 92, 767-788. https://doi.org/10.1007/s11242-011-9932-5

Zhang, Y., Sarma, H., 2012. Improving waterflood recovery efficiency in carbonate reservoirs through salinity variations and ionic exchanges: A promising low-cost "smart-waterflood" approach. Abu Dhabi Int. Pet. Exhib. Conf. 2012 - Sustain. Energy Growth People, Responsib. Innov. ADIPEC 2012 3, 2163-2183. https://doi.org/10.2118/161631-MS 